\title{
Perfiles del coleccionismo barroco: Andrés de Uztarroz y la Descripción de las antigüedades y jardines de don Vincencio Juan de Lastanosa ${ }^{1}$
}

\author{
Alberto Fadón Duarte \\ Universidad Complutense de Madrid
}

Título: Perfiles del coleccionismo barroco: Andrés de Uztarroz y la Descripción de las antigüedades y jardines de don Vincencio Juan de Lastanosa.

Resumen: El presente artículo sondea el poema de Andrés de Uztarroz titulado Descripción de las antigüedades y jardines de don Vincencio Juan de Lastanosa (1647). Para ello, se divide en tres secciones: en primer lugar, se examinan algunas de las características de Vincencio Juan de Lastanosa y de su mansión oscense a la luz de las últimas aportaciones. A continuación se estudia con detalle la descripción lírica de Uztarroz, atendiendo especialmente a su género, estructura, lenguaje y relación con otros textos. Por fin, se analiza su catálogo floral como una manifestación particular de un motivo que gozó de gran fortuna en el Barroco.

Palabras clave: Andrés de Uztarroz, Vincencio Juan Lastanosa, coleccionismo, poesía descriptiva de palacios y jardines, catálogo floral.

Fecha de recepción: 26/4/2021.

Fecha de aceptación: 3/6/2021.
Title: Collecting Profiles in the Baroque: Andrés de Uztarroz and the Descripción de las Antigüedades y Jardines de don Vincencio Juan de Lastanosa.

Abstract: This paper delves into the poem Descripción de las antigüedades y jardines de don Vincencio Juan de Lastanosa (1647) written by Andrés de Uztarroz. To achieve this purpose, it is divided in three sections: first, we offer some notes about the life and mansion of Vincencio Juan de Lastanosa in light of the most recent works. Secondly, the study of the poetic composition focuses on its genre, structure, language and parallels with other texts. Finally, the catalogue of flowers, placed at the end of the poem, is analysed as a particular manifestation of a popular motif in Baroque poetry.

Key words: Andrés de Uztarroz, Vincencio Juan de Lastanosa, Collecting, Country House Poem, Catalogue of Flowers.

Date of Receipt: 26/4/2021.

Date of Approval: 3/6/2021.

1 Quisiera agradecer a los informantes de este artículo su atenta lectura, que me ha permitido matizar algunos conceptos y eliminar numerosas erratas. Asimismo, me gustaría darle las gracias a Jesús Ponce Cárdenas por sus sugerencias sobre las 
Un ensayo pionero sobre Juan Francisco Andrés de Uztarroz (1606-1653) ponderaba con entera justicia la "doble naturaleza de erudito y poeta" que caracterizó al aragonés ${ }^{2}$. La figura y la obra del cronista real ofrecen, de hecho, un perfil complejo que permite profundizar en varios aspectos capitales de la cultura letrada en la España de Felipe IV. A lo largo de una vida principalmente consagrada al cultivo de la historia y ocasionalmente de la poesía, desde la óptica literaria el autor desempeñó un papel destacado en la consolidación del gongorismo en Aragón. Como presidente de la Academia de los Anhelantes desde finales de la segunda década del Seiscientos, con el sobrenombre de El Solitario, Uztarroz llegó a recopilar en un cancionero de 1628 numerosas composiciones de signo culto ${ }^{3}$. Asimismo, en la década de los treinta participó en la polémica gongorina con varios trabajos, lamentablemente hoy perdidos, en los que discutía con algunos detractores del vate andaluz como Quevedo ${ }^{4}$.

traducciones de algunos fragmentos en italiano. El presente estudio se inscribe en el marco del Proyecto "Hibridismo y Elogio en la España Áurea» (HELEA) PGC2018-095206-B-100, financiado por el Ministerio de Ciencia e Innovación y por el Fondo Europeo de Desarrollo Regional (FEDER).

2 Ricardo del Arco y Garay, La erudición española en el siglo XVII y el cronista de Aragón Andrés de Uztarroz, Madrid, CSIC/Instituto Jerónimo Zurita, 1950. Este libro continúa siendo la mejor aproximación al poeta.

3 José Sánchez, Academias literarias del Siglo de Oro español, Madrid, Gredos, 1961, p. 234, no dudaba en afirmar sobre la Academia de los Anhelantes: "Es esta academia, tal vez, la segunda más importante entre las sociedades regionales. Fuera de Madrid, y después de la Academia de los Nocturnos, no existe en España otra que haya ejercido más influencia...”. La obra aludida, en la que el poeta más representado es el propio Góngora, ha sido modernamente editada: Cancionero de 1628, ed. José Manuel Blecua, Madrid, CSIC/Patronato Menéndez Pelayo/Instituto Antonio de Nebrija, 1945. Arco y Garay, op. cit., p. 34, fue el primero en atribuir a Uztarroz la compilación de 1628.

4 Partiendo de la bibliografía elaborada por Latassa en el siglo XVIII, Miguel de Artigas, Don Luis de Góngora. Biografía y estudio crítico, Madrid, Tipografía de la Revista de Archivos, 1925, p. 242, ofrecía la siguiente lista de las obras de Uztarroz sobre Góngora: Defensa de la poesía española respondiendo a un discurso de don Francisco de Quevedo que se halla al principio de las Rimas del maestro fray Luis de León o del bachiller Francisco de la Torre (1632); Antídoto contra la Aguja de navegar cultos (1633); Defensa de los errores que introduce en las obras de don Luis de Góngora don García de Salcedo Coronel, su comentador (1633); Apología por el estilo de don Luis de Góngora y Argote, racionero de la Santa Iglesia de Córdoba, capellán de honor de su 
Su amistad con el noble oscense Vincencio Juan de Lastanosa (16071681) a partir de 1636 le permitió dar rienda suelta a una pasión compartida por las antigüedades, los libros, las medallas, las estampas y la poesía de Góngora que terminaría por cristalizar en la escritura de algunas obras eruditas 5 . Entre ellas, son de especial interés sus dos descripciones de la suntuosa casa de su amigo y mecenas, una en verso y otra en prosa, publicadas en 1647 y en los primeros años de la década de los cincuenta.

El objetivo de este trabajo es examinar la primera de ellas, la composición en verso titulada Descripción de las antigüedades y jardines de don Vincencio Juan de Lastanosa ${ }^{6}$. A pesar de tratarse de una obra de indiscutible interés que nos acerca tanto al coleccionismo aristocrático del siglo XVII como a la retórica del elogio en verso, el poema de Uztarroz apenas ha recibido atención de la crítica. Como honrosas excepciones, no pueden dejar de citarse los comentarios espigados por Ricardo del Arco y Garay, quien editó esta composición en uno de sus volúmenes sobre la erudición seicentista considerándolo una suerte de "impresión lírica [...] del cro-

Majestad (1636). Por otra parte, dentro de una obra historiográfica, Uztarroz confeccionaba un rico catálogo de autores que citaron a Góngora: Defensa de la patria del invencible mártir San Laurencio, Zaragoza, Hospital Real y General de Nuestra Señora de Gracia 1638, pp. 246-248. Para el uso de Góngora entre los historiadores, incluyendo a Uztarroz, véase Muriel Elvira, "La recepción de Góngora entre los historiadores españoles del Siglo XVII", Atalanta, Revista de Letras Barrocas, 6, 2 (2018), pp. 83-116 (pp. 96-99).

5 Para la afición de Lastanosa por Góngora y su uso en sus tratados anticuarios, véase Elvira, ibidem, pp. 104-109.

6 Tomo el texto del impreso original, del que se conserva un ejemplar en la Real Biblioteca del Palacio Real de Madrid: Descripción de las antigüedades y jardines de don Vincencio Juan de Lastanosa, hijo y ciudadano de Huesca, ciudad del reino de Aragón. Descriviala El Solitario a Don Francisco Filhol, lustre, ornamento y elogio de la ciudad de Tolosa, Zaragoza, Diego Dormer, 1647. Existen dos impresos modernos del texto que siguen la tradición textual manuscrita recogida en el siglo XVIII por Félix Latassa en sus Memorias literarias de Aragón, Aragón, Biblioteca Pública de Huesca, Ms. 76, I, pp. 113-130. El primero se incluye en Revista de Archivos, Bibliotecas y Museos, VI (1876), pp. 213 y ss.; y el segundo en Ricardo Arco y Garay, La erudición aragonesa en el siglo XVII en torno a Lastanosa, Madrid, Imprenta Góngora, 1934, pp. 162-171. El manuscrito del Seiscientos se conserva hoy en la Hispanic Society of America, Ms. B2424, f. 13-23. 
nista Uztarroz ante las riquezas arqueológicas del palacio de Lastanosa"7. Pero, sobre todo, son especialmente valiosos los análisis proporcionados por Aurora Egido en su tesis doctoral ${ }^{8}$. Si bien las páginas de la académica de la Lengua Espańola proponen una visión completa del poema, el considerable desarrollo que han conocido los estudios sobre algunas facetas de las letras barrocas como la poesía epidíctica, así como la relectura a la que se ha sometido la figura de Vincencio Juan de Lastanosa en los últimos años, obligan a revisar la descripción de Uztarroz. Para ello, este artículo se articula en tres grandes secciones ${ }^{9}$. En primer lugar, se pone en contexto la figura de Vincencio Juan de Lastanosa, con especial atención a su residencia oscense y sus colecciones. A continuación se ofrece un análisis general de la composición de Uztarroz, atendiendo a su relación con otros poemas descriptivos de palacios y jardines, a su dispositio y elocutio. Finalmente, se ahonda en la última parte del poema, la descripción de las flores que ornaban los jardines oscenses, a la luz de un motivo que conoció un gran desarrollo en la lírica hispana e italiana del barroco.

\section{VINCENCIO JUAN DE LASTANOSA: PERFILES DE UN COLECCIONISTA BARROCO}

A raíz de la publicación de la biografía de Baltasar Gracián en 1913 por Adolphe $\operatorname{Coster}^{10}$ y de las monografías La erudición aragonesa en el siglo XVII en torno a Lastanosa ${ }^{11}$ y La erudición española en el siglo XVII y el

7 Arco y Garay, op. cit., 1934, pp. 161-162.

8 Aurora Egido, La poesía aragonesa del siglo XVII (raíces culteranas), Zaragoza, Institución Fernando/Diputación de Zaragoza, 1979, pp. 250-256.

9 Véase Fermín Gil Encabo, "Perfiles de Lastanosa, ciudadano de Huesca y mecenas de Gracián (estado de la cuestión)", en Mecenazgo y Humanidades en tiempos de Lastanosa. Homenaje a Domingo Ynduráin, eds. Aurora Egido y José Enrique Laplana, Zaragoza, Institución Fernando el Católico e Instituto de Estudios Aragoneses, 2008, pp. 193-252; y la colectánea Vincencio Juan de Lastanosa (1607-1681). Pasión de saber, eds. Ma Carmen Morte García y Carlos Garcés Manau, Huesca, Diputación Provincial de Huesca, 2007.

10 Adolphe Coster, Baltasar Gracián, trad. prólogo y notas Ricardo del Arco y Garay, Zaragoza, Institución Fernando el Católico/Diputación Provincial de Zaragoza, 1947 [1913].

11 Arco y Garay, op. cit., 1934. 
cronista de Aragón Andrés de Uztarroz ${ }^{12}$ —obras que a su vez bebían de las Memorias literarias de Aragón elaboradas por el bibliógrafo Latassa en la segunda mitad del siglo XVIII ${ }^{13}$ — los elogios a la figura de Vincencio Juan de Lastanosa como suntuoso coleccionista, erudito y protector de las artes se convirtieron en un lugar común en los estudios sobre el Siglo de Oro. No es exagerado afirmar que toda la producción crítica sobre el noble oscense hasta los últimos años del siglo XX ha estado marcada por la lectura que de él realizaron este par de estudiosos ${ }^{14}$.

Si bien todavía puede sostenerse una parte de sus interpretaciones, en los últimos años, junto con un conocimiento más detallado de las prácticas nobiliarias de la época, han tenido lugar algunos descubrimientos bibliográficos que merecen ser tenidos en cuenta. En primer lugar, la Biblioteca Nacional de España adquirió en 1993 el manuscrito Genealogía de la noble casa de Lastanosa ${ }^{15}$, importante códice que, amén de incluir discursos genealógicos, cartas y documentos de la familia, iba acompañado de una sugerente colección de grabados sobre la residencia de Huesca y sus jardines. Por otro lado, se ha demostrado que lo que había sido tradicionalmente una importante fuente de información sobre la mansión de Huesca era, en realidad, una falsificación de dudoso valor documental. Nos referimos al texto titulado Las tres cosas más singulares que tiene la casa de Lastanosa en este año 1639 que Adolphe Coster dio a la estampa en $1912^{16}$.

12 Arco y Garay, op. cit., 1950.

13 Félix Latassa, Memorias literarias de Aragón (Biblioteca Pública de Huesca, Mss. 76, 77, 78).

14 Gil Encabo, op. cit.

15 Genealogía de la noble casa de Lastanosa. Epitome sacado de las que escrivieron D. Pedro, Balthasar de Lastanosa; exhibidas en el Processo que hizo Balthasar de Lastanosa en la Villa de Falseto el año 1573, y en la prouanza hecha por don Vincencio Iuan de Lastanosa en la Real Audiencia de Aragón. Año 1628. Ajustada con instrumentos públicos, Annales, Historias impresas y manuscritos, Epitafios y memorias de Iglesias. Illustrabala D. Vincencio Iuan de Lastanosa, Huesca, 1651, Ms. BNE 22609.

16 Adolphe Coster, "Une description inédite de la demeure de don Vincencio Juan de Lastanosa”, Revue Hispanique, 26 (1912), pp. 566-610. La falsedad del documento la puso de manifiesto Fermín Gil Encabo, "Lastanosa y Gracián: en torno a Salastano", en Congreso Internacional "Baltasar Gracián: pensamiento y erudición” (Huesca, 23-26 de mayo de 2001), eds. Aurora Egido, Fermín Gil Encabo y José Enrique Laplana, Huesca/Zaragoza, Instituto de Estudios Altoaragoneses/Institución Fernando el Católico/Gobierno de Aragón, 2003, pp. 19-60 (pp. 23-35). 
La divergencia de la descripción con otras fuentes no solo radica en una exageración del número de colecciones que poseía el propietario aragonés (incluyendo la presencia de animales salvajes), sino en ser la única que narra la visita a los jardines, biblioteca y museo lastanosianos de personajes tan ilustres como el duque de Orleans, hermano de Luis XIII, o Felipe IV. Asimismo, Fermín Gil Cabo ha apuntado cómo el laberinto descrito por el manuscrito apócrifo (pluriviario, manierista) no se corresponde con el que evoca la obra en prosa de Uztarroz y los grabados conservados en la Genealogía (univiario, clásico), de mediados de siglo ${ }^{17}$ :

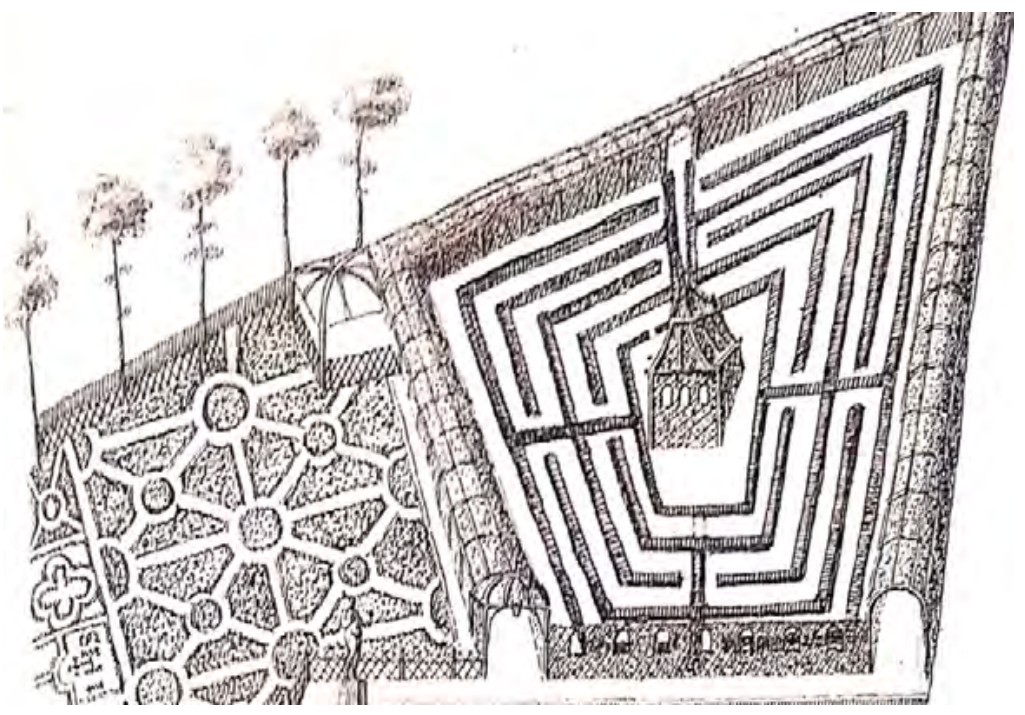

Fig. 1, Ms 22.609 BNE, f. 233r.

Con todo, la residencia, jardines y colecciones de aristócrata aragonés que podemos reconstruir con el resto de fuentes no resultan menos fascinantes. Si bien se ha apuntado que este palacio edificado en la anterior centuria por los antepasados de Vincencio Juan de Lastanosa era "un edificio de rango notable pero común desde el punto de vista constructivo entre las casas de la ciudad" ${ }^{18}$, los aspectos más deslumbrantes —al igual que

17 Gil Encabo, ibidem, pp. 25 y 27.

18 Carmen Gómez Urdáñez, "Entre erudición y naturaleza, arquitectura”, en Vincencio Juan de Lastanosa (1607-1681). Pasión de saber, eds. M. ${ }^{a}$ Carmen Morte García 
sucedía con otros edificios españoles de la época como el Palacio del Buen Retiro- quedaban reservados a los jardines y a las estancias interiores.

El museo del culto oscense ofrecía tal variedad que cabe emparentarlo con las Wunderkammer o gabinetes de curiosidades diseñados por algunos aristócratas europeos desde la segunda mitad del siglo XVI ${ }^{19}$. Por citar algunos ejemplos, las posesiones de Lastanosa incluían numerosos libros, escritorios de lujo, esculturas, pinturas y estampas, armas, piedras preciosas, monedas y medallas antiguas, mapas, instrumentos científicos, naturalia e ídolos americanos ${ }^{20}$. Las colecciones de piedras preciosas y medallas antiguas constituían, sin duda, uno de los rasgos distintivos del gabinete del refinado aristócrata, tal como evidencian los detallados versos que les dedicó Uztarroz en su descripción poética. Asimismo, Lastanosa, en su faceta de estudioso, consagró sus esfuerzos a la elaboración de algunos tratados sobre las medallas y las piedras preciosas: Dactilotheca, Museo de las medallas desconocidas españolas, Piedra de toque de la moneda jaquesa y Medallas romanas explicadas ${ }^{21}$.

y Carlos Garcés Manau, Huesca, Diputación Provincial de Huesca, 2007, pp. 5967 (p. 60).

19 Si bien la información concreta que los autores ofrecen sobre Lastanosa presenta algunos problemas por el papel que conceden a la descripción apócrifa de 1639, la monografía de Miguel Morán y Fernando Checa sobre el coleccionismo en Espańa sigue siendo valiosa para conocer los orígenes y la naturaleza contexto cultural en el que se desenvolvió el museo del aristócrata oscense: El coleccionismo en España. De la cámara de maravillas a la galería de pinturas, Madrid, Cátedra, 1985.

20 Manuel José Pedraza García, "La biblioteca de Vincencio Juan de Lastanosa", en Vincencio Juan de Lastanosa (1607-1681). Pasión de saber, eds. M. ${ }^{a}$ Carmen Morte García y Carlos Garcés Manau, Huesca, Diputación Provincial de Huesca, 2007, pp. 87-95; María Paz Aguiló Alonso, "Muebles y escritorios en las colecciones de Vincencio Juan de Lastanosa”, en ibidem, pp. 97-107; Arturo Ansón Navarro, "La pintura en las colecciones de Vincencio Juan de Lastanosa", en ibidem, pp. 109115; Álvaro Soler del Campo, "La armería de Vincencio Juan de Lastanosa", en ibidem, pp. 117-123; Almudena Domínguez Arranz, "Monedas, medallas y piedras preciosas en el 'Museo discreto' de Vincencio Juan de Lastanosa”, en ibidem, pp. 125-133; Agustín Hernando, "El placer de pasearse por lugares: la posesión de una exquisita colección cartográfica", en ibidem, pp. 147-157; Pedro Ruiz Castell, "Instrumentos científicos en las colecciones de Vincencio Juan de Lastanosa", en ibidem, pp. 159-165; y Eladio Lińán Guijarro, "Objetos naturales en las colecciones de Vincencio Juan de Lastanosa”, en ibidem, pp. 167-175.

21 Exceptuando la Dactiloteca, se conservan en la actualidad los otros tres tratados. 
En lo que respecta a la huerta y los jardines, se ha señalado su importancia como uno de los principales testimonios de la jardinería aristocrática en la España del siglo XVII. En su conformación se daban cita algunos elementos de tradición morisca como "su diversificación espacial en diferentes recintos ajardinados y [...] la combinación de especies vegetales ornamentales y utilitarias en ellos" con otros de origen italiano como "la supervivencia de un potente eje regulador, la existencia de arte topiaria y, probablemente, el desarrollo de un complejo programa iconográfico, así como las plantaciones ordenadas en sistemas modulares y otros múltiples elementos"22. Afortunadamente, gracias al manuscrito de la Genealogía podemos hacernos una idea precisa de su disposición:

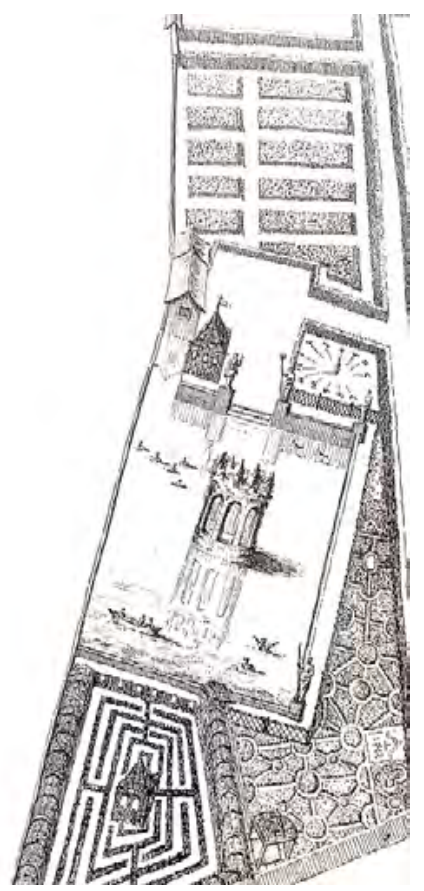

Fig. 2, Ms 22.609 BNE, f. 232r.

Sin duda uno de los elementos más llamativos de los jardines era la isla artificial que se erguía en el centro del estanque. Se trata de un recurso

22 Aurora Rabanal Yus, "Los jardines de Vincencio Juan de Lastanosa", en ibidem, pp. 69-77 (p. 69). 
ornamental procedente de la época de Felipe II, utilizado en palacios como La Fresneda, el Buen Retiro o el del duque de Béjar y empleado también en destacados jardines italianos como los de la Villa Lante en Bagnaia o el jardín de Boboli en el Palacio Pitti de Florencia. Curiosamente, el artificio no llamó la atención de Uztarroz poeta, quien apenas dedica atención a los entornos acuáticos del jardín. En la descripción en prosa elaborada posteriormente, en cambio, sí que encontramos una pintura sugerente del escollo:

en la mitad [del estanque] hay un edificio redondo que formando ocho puertas y otros tantos pilares, sustentan unos arcos que rematan en lo alto con alguna desigualdad. El adorno de esta obra es de piedra limada tosca, de cristales de ladrillo dos veces cocido, corales blancos, piedras cuajadas del agua, villas, castillos, torres, ermitas, caseríos de pastores, ganado, perros, vivientes y brutos; y todo junto parece una viva representación de las ruinas romanas, donde por su grande entre los estragos se ve un jardín, una casa y una viña; porque si se observa aquel grupo, parece una gran montańa, donde se observan las cosas que se han referido ${ }^{23}$.

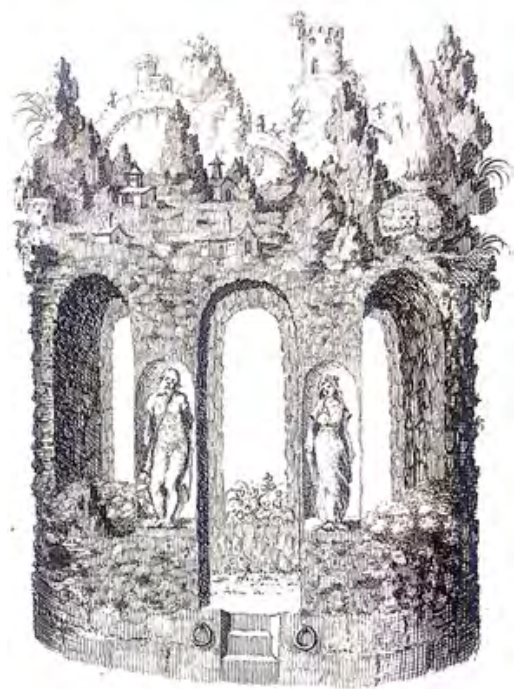

Fig. 3, Ms. 22.609 BNE, f. 230 r.

23 Cito por la transcripción de Arco y Garay, op. cit., 1934, pp. 249-250. 
Por otro lado, aunque a la cuestión de las flores volveremos más adelante, cabe dejar apuntado que Vincencio Juan de Lastanosa era también aficionado a coleccionar plantas exóticas, suministradas muchas veces por su red de contactos europeos. En la Narración, obra descriptiva elaborada por él mismo, recordaba que poseía "un espacioso estanque, árboles silvestres y fructíferos, multitud de flores sin que falten las que gozan los más remotos países para cuyo logro he tenido la correspondencia del docto Filhol en Tolosa"24. François Filhol (1583?-1648), presbítero hebdomanario de la catedral de San Esteban de Toulouse, también coleccionista y amigo del noble oscense y de Uztarroz, sería el destinatario de la Descripción de las antigüedades y jardines de don Vincencio Juan de Lastanosa ${ }^{25}$.

\section{Elogio y Memoria en la descripción de ANdrés de UztarroZ}

En los últimos años del reinado de Felipe II, a la zaga de modelos clásicos, neolatinos e italianos, floreció en España un género de literatura epidíctica que recientemente ha sido denominado por la crítica poesía descriptiva de villas, palacios $y$ jardines ${ }^{26}$. Esta modalidad, cuyo origen se remonta en última instancia a dos de las Silvas de Estacio (I, 3; II, 2), constituía

24 Narración de lo que pasó a Don Vincencio Juan de Lastanosa a 15 de octubre del año 1662 con un religioso docto y grave (BNE, Ms. 18727/55).

25 Existen algunos estudios consagrados al interesante erudito galo: véase, por ejemplo, Maurice Caillet y Robert Mesuret, "François Filhol, toulousain, son oeuvre et son cabinet (1583?-1645)", Mémories de la société archéologique du midi de la France, XXIX (1963), pp. 99-137 y VII-XI. Más recientemente, Christian Péligry, "François Filhol, chanoine hebdomadier de la cathédrale Saint-Etienne de Toulouse (¿1583? - 1648): l'homme, l'érudit, son cabinet de curiosités, ses relations aragonaises", Mémoires de la Société archéologique du Midi de la France, LXXIII (2018), pp. 275-296.

26 Carlo Caruso, "Poesia umanistica di villa", en Feconde Venner le carte. Studi in onore di Ottavio Besomi, ed. Tatiana Crivelli, Bellinzona, Edizioni Casagrande, 1997, pp. 272-294; Jesús Ponce Cárdenas y Ángel Rivas Albaladejo, El jardín del conde de Monterrey. Arte, naturaleza y panegírico, Salamanca, Delirio, 2018; Jesús Ponce Cárdenas, "Pintura y Panegírico. Usos de la écfrasis en Manoel de Galhegos", Versants, 3, 65 (2018), pp. 97-123; Jesús Ponce Cárdenas, "El Panegírico al Buen Retiro de José Pellicer de Salas y la tradición de las poesie di villa", e-Spania, 35 (2020), pp. 1-22; y Alberto Fadón Duarte, "Introducción”, en Lope de Vega, Descripción de La Tapada, Madrid, Giardini di Bomarzo, 2020, pp. 7-94. 
fundamentalmente el elogio indirecto de un rico propietario a través de la pintura pormenorizada de una villa de recreo o palacio, atendiendo tanto a la arquitectura y a las colecciones artísticas como a los jardines y espacios exteriores. Entre sus cultores encontramos literatos tan señeros como Lupercio Leonardo de Argensola, Lope de Vega, Quevedo, Pedro Soto de Rojas, Bernardino de Rebolledo o Francisco de Trillo y Figueroa. En el caso español, los lugares elogiados incluían algunos de los principales sitios reales (Aranjuez, el Palacio del Buen Retiro, El Pardo), destacadas residencias nobiliarias (Los jardines de Abadía del duque de Alba, la residencia y jardines del conde de Monterrey en Madrid, el Palacio Buenavista del cardenal Bernardo de Sandoval y Rojas) e importantes santuarios, conventos y monasterios (La Cartuja de Aula Dei, el Monasterio de San Jerónimo de Guisando, el Santuario de Nuestra Seńora de la Cabeza en Motril, el Monasterio de Montserrat).

La Descripción de las Antigüedades y Jardines de Vincencio Juan de Lastanosa elaborada por Uztarroz se inserta, sin lugar a dudas, dentro de esta sugestiva modalidad genérica. Aunque no sabemos hasta qué punto el erudito vate pudo estar familiarizado con algunos de los principales modelos españoles e italianos del género, de seguro conocía la composición que Lupercio de Argensola había consagrado a Aranjuez varias décadas antes, dado el inmenso prestigio del que gozaba el poeta en su tierra. Asimismo, contamos con un valioso testimonio que prueba su familiaridad con otra estimable poesía descriptiva aragonesa publicada en 1637, diez años antes. Nos referimos a la composición de Miguel Dicastillo Aula $D e i$, dedicada al homónimo monasterio cartujo de Zaragoza. Se trata de un extenso poema encomiástico en el que, a juicio de Aurora Egido, se da la mano el modelo de la descripción arajovense de Lupercio Leonardo de Argensola con las huellas gongorinas ${ }^{27}$. En relación con Uztarroz, lo que nos interesa es el soneto que incluyó en los preliminares del libro:

No son de Estacio, no las soledades, o, lector, ni del grave mantuano, las que agora describe docta mano copiando cuantas hay frondosidades:

27 Miguel de Dicastillo, Aula de Dios, cartuxa real de Zaragoza (Zaragoza, 1637), ed. facsímil de Aurora Egido, Zaragoza, Libros Pórtico, 1978. 
Selvas sí, donde en sacras amistades viven los hijos de aquel Sol germano, cuyo feliz contacto soberano a las peñas vistió de amenidades.

Descaminado, errante peregrino será aquel que a silva religiosa se niegue por buscar otro camino

Empero si de AUGUSTA es la estudiosa AULA DE DIOS, malogrará el destino el que no atienda a su lección gloriosa ${ }^{28}$.

Más allá de evidenciar las relaciones que Miguel Dicastillo mantenía con el principal miembro de la Academia de los Anhelantes, pone de manifiesto algunos de los modelos a través de los cuales Uztarroz pudo interpretar la compleja silva. Para el vate cesaraugustano, la composición de Miguel Dicastillo se emparenta (a pesar de las fórmulas negativas) con la producción de Estacio y de Virgilio. Si bien no especifica las obras concretas, lo más probable es que el aragonés tuviese en mente aquellas dominadas por la tonalidad descriptiva, esto es, las Silvas en el caso de Estacio y las Bucólicas y las Geórgicas en el de Virgilio. Por otro lado, el recuerdo de Góngora (especialmente marcado en el noveno verso) sirve para ligar Aula Dei con el universo de las Soledades. La Descripción de los jardines y antigüedades, si bien se aleja del modelo eclógico y didáctico virgiliano y no es particularmente prolija en estilemas de signo gongorino, comparte con algunas de las Silvas de Estacio, junto con el marco general de la descripción en verso de una villa, el gusto por demorarse en la pintura verbal de las suntuosas piezas de coleccionismo que poseía su propietario ${ }^{29}$.

28 Dicastillo, ibidem, ff. preliminares.

29 Son varios los fragmentos que se pueden mencionar. En la silva I, 3 (vv. 47-51), consagrada a la celebración de la villa tiburtina de Manilio Vopisco, se lee: "Vidi artes veterumque manus variisque metalla / viva modis. labor est auri memorare figuras / aut ebur aut dignas digitis contingere gemmas; / quicquid et argento primum vel in aere minori / lusit, et enormes manus est experta colossos" (Allí he visto obras de arte de antiguos artesanos y yacimientos vivos componiendo su múltiple armonía. El 
Entrando ya en el texto que nos ocupa, cabe proponer la siguiente estructura general, dividida en cinco partes principales:

1. Dedicatoria (vv. 1-17)

2. Exterior de la casa (vv. 18-23)

3. Interior del palacio de Lastanosa (vv. 24-279)

3.1. Monedas y medallas (vv. 24-159)

3.2. Cerámicas de Sagunto (vv. 160-165)

3.3. Dactiloteca (vv. 166-173)

3.4. Empresa Ave Fénix (vv. 174-185)

3.5. Biblioteca (vv. 186-191)

3.6. Pinturas y estampas (vv. 192-210)

3.7. Segunda biblioteca con el retrato de la esposa (vv. 211-234)

3.8. Escritorio con esculturas y mapas (vv. 235-252)

3.9. Armería (vv. 253-262)

3.10. Alacena con naturalia (vv. 263-271)

3.11. Recapitulación de los adornos del interior (vv. 272-279)

4. Jardín adyacente (vv. 280-396)

recuerdo sería fatigoso de las preseas de oro, los marfiles, las gemas dignas de adornar los dedos, y cuanto ha sido un juego del artista - primero con la plata o con el bronce, menos valioso-, como un ensayo para plasmar colosos gigantescos'). Igualmente, entre las alabanzas de las riquezas que poseía Polio Félix en su villa sorrentina (II, 2), no podían faltar las obras de arte (vv. 63-72): "Quid referam veteres ceraeque aerisque figuras? I si quid Apellei gaudent animasse colores, I si quid adhuc vacua tamen admirabile Pisa / Phidiacae rasere manus, quod ab arte Myronis / aut Polycleteo iussum est quod vivere caelo, I aeraque ab Isthmiacis auro potiora favillis, I ora ducum ac vatum sapientumque ora priorum, / quos tibi cura sequi, quos toto pectore sentis / expers curarum atque animum virtute quieta / compositus semperque tuus" ("¿Qué decir de las viejas obras de arte, las pinturas y bronces, todas las que se gozan de haber vivificado los colores de Apeles, todas las que, admirables, esculpieron las manos de Fidias, aun cuando estaba Pisa despoblada, y las que cobraron vida obedeciendo al arte de Mirón o al cincel de Policleto, y los bronces, de más valor que el oro, salidos de las fundiciones del Istmo, los bustos de caudillos, de poetas y sabios de antaño a quien procuras imitar, a quienes amas de todo corazón, exento de inquietudes, lleno tu espíritu de serena virtud y dueño siempre de ti mismo?'). Los textos latinos están tomados de Statius, Silvae, edited and translated by D. R. Shackleton Bailey with corrections by Christopher A. Parrot, Cambridge-London, Harvard University Press, 2015, pp. 44; 106-108. Las traducciones proceden de Silvas, ed. Francisco Torrent Rodríguez, Madrid, Gredos, 1995, pp. 51 y 94-95. 
4.1. Visión general de la huerta (vv. 280-307)

4.2. Catálogo floral (308-370)

4. 3. Evocación de los espacios acuáticos y recuerdo de la esposa fallecida (vv. 371-396)

5. Conclusión (vv. 397-408)

La dispositio, ante todo, evidencia que "el poema sobre las riquezas lastanosianas contiene dos partes, una que aboga por el Arte, otra por la $\mathrm{Na}$ turaleza", en palabras de Aurora Egido ${ }^{30}$. Antes de ocuparse de la descripción de las colecciones, como era habitual en las obras poéticas de cierto aliento, el texto de Uztarroz se abre con una dedicatoria constituida por la invocación al amigo común de ambos y destinatario de la obra, el "docto Filhol" de Toulouse, y con una propositio dividida en tres partes que acota el tema. Se trata de celebrar, fundamentalmente, "aquella biblioteca prodigiosa" (v. 5) y "lo raro, lo exquisito del museo / de nuestro dulce amigo Lastanosa" (vv. 8-9) dejando de lado, por la grandeza del lugar, "las piezas numerosas de su casa” (v. 14).

En lo que respecta al destinatario, cabe recordar que Uztarroz, tres años antes, había elaborado un elogio en prosa de su colección bajo el título Diseño de la insigne y copiosa biblioteca de Francisco Filhol, presbitero y hebdomanario en la Santa Iglesia Metropolitana del Protomártir San Esteban de la ciudad de Tolosa ${ }^{31}$. Se trata de una obra interesante en la línea del texto en prosa que consagraría al palacio oscense en la década de los cincuenta. El Diseño, además, iba precedido por un erudito prólogo en el que el ingenio aragonés elogiaba los estudios de la Antigüedad y a toda una nómina de varones que los habían cultivado, incluyendo naturalmente a Lastanosa. Cabe apuntar, por otro lado, que a pesar de afición al coleccionismo y a las antigüedades compartida por los tres amigos, Uztaroz se refiere al francés aquí en su dimensión de alumno de las Musas:

30 Egido, op. cit., p. 251. Cabe, asimismo, señalar que la estructura descriptiva consistente en evocar primero el exterior, después el interior y, finalmente, los jardines se emparenta con algunos de los más prestigiosos dechados clásicos como la descripción del palacio del Alcínoo en el séptimo canto de la Odisea o la pintura de la morada de Manilio Vopisco realizada por Estacio en una de sus silvas (I, 3).

31 Diseño de la insigne y copiosa biblioteca de Francisco Filhol, presbitero y hebdomanario en la Santa Iglesia Metropolitana del Protomártir San Esteban de la ciudad de Tolosa, Huesca, Francisco de Larumbre, 1644. 
"Docto Filhol, si al plectro destemplado / atiende numerosa / tu musa, / honor ilustre de Tolosa" (vv. 1-3) ${ }^{32}$.

Tras estos versos introductorios, la evocación de Uztarroz se abre con la fachada del palacio, presidida por una estatua de Hércules:
Antes de entrar en ella
una torre eminente se descuella,
en cuyo fin se admira
la estatua del galán de Deyanira,
que donde todo es claras suspensiones,
la entrada ha de ofrecer admiraciones (vv. 18-23).

Es probable que la mención de la estatua como único elemento de la fachada obedezca a la sencillez de esta, que no se corresponde con el universo de maravillas, admiración y prodigios que el poeta quiere presentar. Como evidencian otros testimonios, se trata de una escultura de plomo con un Alcides desnudo sosteniendo el globo terrestre ${ }^{33}$. Uno de los grabados del manuscrito de la Genealogía nos permite apreciarla en su justa medida:

32 Según Cailet y Mesuret, op. cit., 1963, la única obra poética que en la actualidad se conserva de François Filhol es el Oracle poétique, publicado en 1619 (pp. 100101; 111-119). Uztarroz, en su descripción de 1644, incluye este libro junto con toda una serie de obras impresas y manuscritas del autor. Véase a modo de ejemplo: Cariños fúnebres al fallecimiento del Pontifice Paulo V(1621), Prosopopeya de La Rochela a la villa de Montalbán, exhortándole a la obediencia de su rey (1629), Octava del augustísimo sacramento del altar, etc. Véase Uztarroz, op. cit., 1644, pp. 25-27.

33 "En la esquina de este edificio que mira al Mediodía se levanta una torre cuadrada, de la misma materia, dando fin con un coloso de Alcides, de chapería de plomo, que ilustra sobre sus espaldas un globo celeste", en Arco y Garay, op. cit., 1934, p. 222. Uztarroz también compuso un romance burlesco sobre esta escultura, del que da noticia Latassa en sus memorias literarias y, posteriormente, Arco y Garay. 


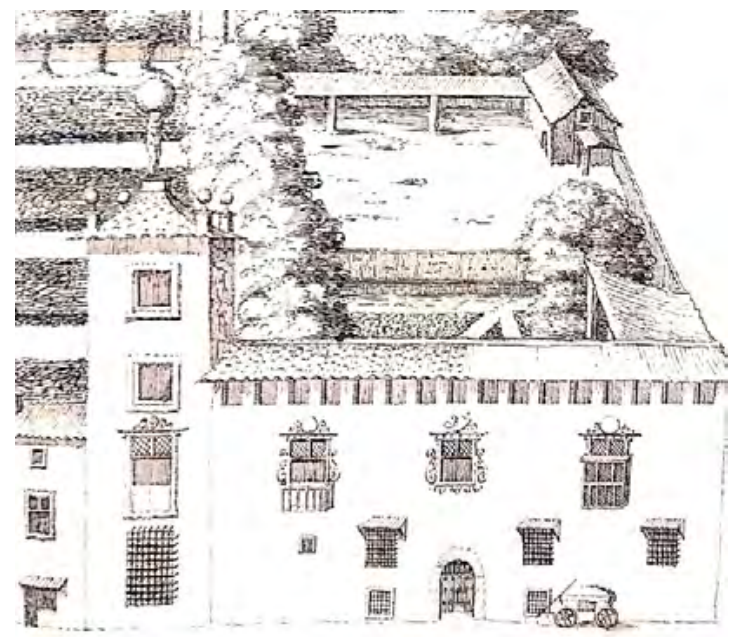

Fig. 4, Ms. 22.609 BNE, f. 229r.

Una vez en el interior, Uztarroz incluye una extensa serie de versos sobre las colecciones de medallas. Aunque este trabajo no pretende ahondar en todas las implicaciones del complejo pasaje, conviene apuntar algunos aspectos. En primer lugar, el fragmento se divide en varios subapartados que, en gran medida, se corresponden con la manera en que las medallas estaban ordenadas en los diversos escritorios de la casa de Lastanosa. Por ejemplo, una primera colección está integrada por medallas romanas (vv. 30-49), anteriores a la época del Imperio, acompañadas de una serie de retratos, estampas o grabados ('traslados elegantes'). A continuación, parece que se mencionan las medallas españolas antiguas (incluyendo romanas) que el noble oscense había investigado en sus tratados, dando lugar así a un elogio más explícito:

Aquí logró el deseo distribuyendo en una y otra parte las ancianas memorias del Museo que dispuso la lima y sacó el arte, haciendo las medallas conocidas que labró nuestra España antiguamente, y por esta razón desconocidas las llamaron diversos escritores; 
pero desvanecidos los errores,

Hesperia deberá a su celo ardiente

los antiguos blasones y decoro

que en aquel siglo merecieron de oro (vv. 50-61).

El agradecimiento del poeta a Lastanosa por sus aportaciones a la numismática española va de la mano de la finalidad patriótica, común en la historiografía de la época, que ya el patrón oscense señalaba en su Museo de las medallas desconocidas: "Mis deseos son representar a la república literaria los trofeos antiguos, las memorias ciertas de España en el Museo de las medallas desconocidas para que los ingenios doctos y sutiles [...] tomen las plumas en honra de nuestra nación" ${ }^{34}$.

Tras esta alusión directa al trabajo del propietario, se incluyen varios versos en los que se reflexiona vagamente sobre el paso del tiempo y las antigüedades hasta centrarse en las gavetas de un suntuoso escritorio que acoge las medallas de Cesar y de los emperadores ${ }^{35}$. Lo más llamativo del pasaje es que Uztarroz, en lugar de describir las medallas con los emperadores, se centra principalmente en las emperatrices, celebrando en primer lugar la belleza que muestran en las monedas y posteriormente comparándolas con las mujeres españolas de su época:
De las Emperatrices resplandece
el donaire, la gala y la hermosura, observada hasta hoy en la escultura
del bronce, que aun el tiempo no envejece:
aquí de sus tocados y su pelo

34 Lastanosa, Museo de las medallas desconocidas españolas, Huesca, Juan Nogués, 1645, p. 2.

35 El escritorio, con relieves que incluyen historias (v. 97), podría corresponderse con uno de los descritos en la Narración. Remito a Vincencio Juan de Lastanosa, $o p$. cit, f. 173r: "El 10 de marfil historiado, de más de medio relieve una dilatadísima historia con grandísima perfección, el segundo es de ébano y plata dividido en lóculos con retratos de dioses emperadores y emperatrices de relieve de perfectísima escultura en piedras preciosas. Los dos escritorios que se siguen a la parte del medio. El $1^{\circ}$ de medallas dividido en noventa gavetas y cada una en 18 lóbulos distintos, en ellos distribuidos medallas de emperadores y emperatrices y otras de griegos, hebreos, púnicas y españolas antiguas, empezando las romanas en Julio César y prosiguiendo la sucesión del imperio". 
el gusto brilla y luce su desvelo, aunque no le llevaban tan prendido como suelen las damas españolas; bien que algunas en forma de amapolas o castañas le dan un fin airoso: otras suelto y tendido, sólo en una lanzada detenido, el ornato encumbrado, ignominioso, la jaulilla ninguna usó, que fuera dejar lo augusto y parecer ramera (vv. 104-118).

Una vez realizada una alusión más detallada a una de las emperatrices, Mesalina (vv. 119-132), el historiador zaragozano pasa rápidamente revista a otras dos colecciones de monedas. La primera está formada por "las medallas en donde resplandecen / los renombres antiguos" (vv. 134135) y la segunda por "las católicas medallas" (v. 150).

Podría postularse que la extensión del pasaje de las monedas obedece no solo al especial interés que tenía en ellas Vincencio Juan de Lastanosa, sino a que se trataba de una afición compartida por Andrés de Uztarroz y François Fihol. Según el Diseño de la insigne y copiosa biblioteca, este poseía:

medallas imperiales, colocadas en cien gavetas, cubiertas de becerro carmesí, y en cada una, a trechos diferentes, diferentes molduras doradas de hierros sutiles y primorosos, el número de las monedas casi tres mil, demás de las griegas, de las góticas y de las princesas. El número de las extranjeras es copiosísimo; las consulares tiene en diferente puesto y son hasta doscientas y setenta por alfabeto desde la familia Aburia hasta la Volteya, de suerte que entre todas posee más de mil y doscientas de plata; las de oro son pocas, pero aprovéchanle para la continuación de sus empleos literarios ${ }^{36}$.

Asimismo, según leemos en esta obra descriptiva, el presbítero galo había elaborado algunos tratados sobre la materia que permanecieron manuscritos: Camarín de las medallas de los pontifices romanos; Camarin de las medallas griegas, de las cuales tiene doscientas de las más raras que se hallan en Europa; Camarín de las medallas consulares, por orden alfabético, desde la

36 Uztarroz, op. cit., 1644, pp. 6-7. 
familia Aburia hasta la Volteya; Camarin de las medallas imperiales, donde prueba las facciones, empresas y triunfos que los emperadores obraron en el discurso de sus vidas, sacados de los reversos de ellas, con las autoridades de los historiadores puestas en el margen; Camarin de las medallas de las emperatrices en número de doscientas y cincuenta y Tratado de las medallas de las princesas y mujeres ilustres ${ }^{37}$. Según evidencian el catálogo de las colecciones y los manuscritos, los intereses numismáticos de ambos eruditos ofrecían perfiles de gran semejanza. No se ha de olvidar, por otro lado, que Uztarroz poseía también su propia colección de monedas que llegaría a prestar a Vincencio Juan de Lastanosa para la elaboración de su Museo de las medallas desconocidas ${ }^{38}$.

El resto de la descripción de los interiores no se demora particularmente en la evocación de ninguna colección. A continuación de las medallas, se recuerdan brevemente "los barros de Sagunto artificiosos" (v. 160) celebrados por Marcial en algunos de sus epigramas ("la musa sutil bilbilitana”, v. 163) ${ }^{39}$. Esta industria alfarera valenciana, que gozó de gran fama en la Antigüedad, había sido mencionada unas décadas antes por un importante precursor de la historiografía secentista, Ambrosio de Morales: "Y he pensado muchas veces que estos debían ser los vasos que labraban en Murvedre, cabe Valencia, y eran de tanta estima que los llevaban hasta Roma y los estimaban allá como por versos de Marcial y por Plinio y otros parece" ${ }^{\prime 0}$. Además, es probable que tanto la referencia como la propia posesión de estos adornos sea fruto de un hecho acontecido unos pocos años antes, un hallazgo arqueológico local que menciona Lastanosa en su Museo: "labraban [en Sagunto] vasos de búcaro purpúreo, de los

37 Uztarroz, ibidem, pp. 28-30.

38 A este respecto, pueden citarse algunos pasajes de la obra de Lastanosa: "La medalla once tiene entre sus antigüedades el doctor Juan Francisco Andrés"; "Tiene esta medalla el doctor Juan Francisco Andrés en su biblioteca"; "La moneda treinta tiene palma en la haz y en el reverso y las ofrece la Antigüedad a su dueño, el doctor Juan Francisco Andrés, por lo mucho que trabaja en su investigación" (Lastanosa, op. cit., 1645, pp. 71, 74, 77).

39 IV, 46; VIII, 6; XIV, 108.

40 Ambrosio de Morales, Las antigüedades de las ciudades de España, Alcalá de Henares, en casa de Juan Íniguez de Lequerica, 1575, p. 5. Véase también Antonio Chabret, Sagunto. Su historia y sus monumentos, tomo II, Barcelona, Tipografía de los sucesores de Ramírez y C., 1888. 
cuales se hallaron muchos fragmentos en la ciudad de Huesca, año mil seiscientos treinta y tres, abriendo los fundamentos para una capilla que se edificó en la Iglesia de San Pedro el Viejo" ${ }^{41}$.

Inmediatamente después de los barros se inserta un pequeño fragmento sobre la dactiloteca, del que cabe reseñar el sobrepujamiento con la colección de un erudito amberino del siglo $\mathrm{XVI}^{42}$ :
Ya que los ricos metales
adornan su Museo,
para mayor recreo
de los más escondidos minerales
brillan piedras preciosas,
en número y colores tan copiosas,
que el tesoro abundante de Gorleo
el vencimiento cede y el trofeo (vv. 166-173).

Abraham Gorlaeus (1549-1608), estudioso que "ricercava soprattutto gli anelli e le pietre intagliate, e ne formò un' ampia raccolta”, había publicado a finales del siglo XVI una obra popular entre los amantes de las antigüedades titulada Dactyliothecae seu annulorum sigillarium quorum apud priscos tam graecos quam romanos usus, ex ferro, aere, argento or auro promptuarii ${ }^{43}$. Se trata de un anticuario con el que estaban familiarizados tanto Lastanosa ${ }^{44}$ como Filhol, quien además también poseía una dactiloteca "no menos rara que inestimable" 45.

Lo que sigue a la colección de piedras es una alusión a uno de los emblemas del refinado aristócrata, el Ave Fénix. Aunque los versos no dejan

41 Lastanosa, op. cit., 1645, pp. 104-105.

42 Para el uso de este término, véase E. R. Curtius, Literatura europea y Edad Media Latina, Madrid, Fondo de Cultura Económica, 1995, pp. 235-239.

43 AA. VV., Biografia universale antica e moderna ossia storia per alfabeto della vita pubblica e privata di tutte le persone che si distinsero per opere, azioni, talenti, virtu' e deliti, vol. 25,Venezia, Presso Gio. Battista Missiaglia, 1825.

44 Uno de sus tratados, hoy perdido, llevaba por título Dactiloteca. En el Museo de las medallas desconocidas españolas, op. cit., 1645, p. 120, también se alude al erudito flamenco: "que no me acuerdo haber visto mención de ellas sino en Gorleo, que trae tan pocas que no creo pasan de tres, porque ha años que le vi".

45 Uztarroz, op. cit., 1644, p. 9. 
claro si se encontraba representado en algún objeto o lugar de la estancia, es probable que decorase la portada de un texto de Lastanosa:

El pájaro de Arabia, que eterniza

en su propia ceniza

las plumas que el sol dora

cuando a ser más augusto lo mejora,

es su empresa elegante,

y en ella simboliza,

de las antigüedades la nobleza,

pues remueva en lo anciano su belleza,

y en aquellos desmayos

bebiendo de Titán los rubios rayos,

sin padecer horrores

entre luces renace y entre olores (vv. 174-185).

Un grabado en el manuscrito de la Genealogía nos permite apreciar en detalle la empresa, en una de sus versiones gráficas:

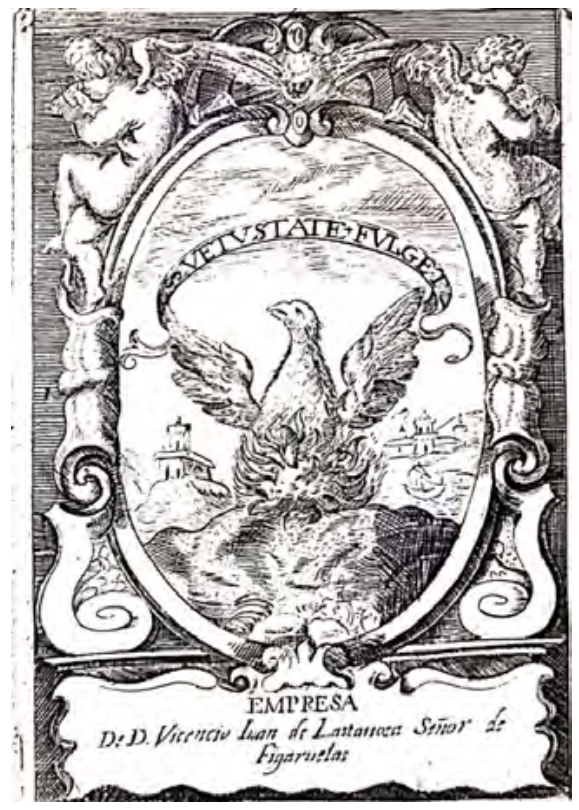

Fig. 5, Ms. 22.609 BNE, f. 57r. 
El lema VETVSTATE FVLGET ('con la antigüedad — de su familiaresplandece') se corresponde en gran medida con lo descrito en los versos de Uztarroz y resulta particularmente acorde a la visión de la Antigüedad ofrecida por el poema ${ }^{46}$.

No presentan un especial interés los versos siguientes, dedicados a las dos bibliotecas y a un rincón con pinturas y estampas, si exceptuamos una pequeña alusión a los estantes que guardaban los recuerdos de la malograda cónyuge de Lastanosa, la sevillana Catalina Gastón (1612-1644), muerta dramáticamente de sobreparto tres años antes:

\author{
Los lúgubres estantes \\ perfilados de oro, los amantes \\ recuerdos representan de la esposa \\ de nuestro docto amigo, que reposa \\ en los pensiles de la gloria amenos (vv. 217-221).
}

Se trata de un motivo que Uztarroz recupera al final del poema, cuando evoca los espacios acuáticos del jardín. Dejando de lado las bibliotecas, la revisión de los interiores se completa con la rápida mención de un escritorio con esculturas y mapas (vv. 235-252), la armería (vv. 253-263) y la alacena con naturalia (vv. 263-271) integrada por esqueletos, corales, cristales de roca "y otros prodigios que por imperfetos / merecen alabanzas y concetos" (vv. 268-269).

Antes de entrar en la conformación del jardín, que estudiaremos a fondo en el siguiente apartado, conviene decir un par de palabras sobre la elocutio del poema. Dado que estamos ante un poeta que escribió varios tratados en defensa de Góngora, parece lícito preguntarse hasta qué punto la composición está marcada por el estilo culto.

Lo primero que llama la atención, tal como apuntaban los pioneros análisis de Aurora Egido, es que "el poema destila clasicismo y equilibrio", si bien "la musa de Uztarroz tiene algunos levísimos toques culteranos" ${ }^{47}$.

46 Véase Sagrario López Poza, "Los emblemas del conde de Guimerá, en Mecenazgo y Humanidades en tiempos de Lastanosa. Homenaje a Domingo Ynduráin, eds. Aurora Egido y José Enrique Laplana, Zaragoza, Institución Fernando el Católico/Instituto de Estudios Aragoneses, 2008, pp. 451-457 (pp. 454-457).

47 Egido, op. cit., p. 255. 
Entre ellos, cabría apuntar de manera genérica el uso de fórmulas adversativo-aditivas, discretos hipérbatos, algunas perífrasis y una cierta tendencia a las bimembraciones y trimembraciones, que en ningún caso son una característica exclusiva de Góngora. Este último aspecto de la construcción versal tiene una especial importancia en la composición, no solo por su abundancia, sino por ser uno de los recursos predilectos para enumerar algunas de las colecciones. La armería, por ejemplo, es presentada en los siguientes términos:
admírase en su estancia
tanta diversidad y extravagancia
de cotas, de lorigas y de arneses,
de espadas, de rodelas y paveses,
de ballestas, pistolas, coseletes,
de jabalinas, dardos y mosquetes (vv. 255-260).

En cualquier caso, la relación con la poesía del cordobés la evidencian detalles más interesantes. En un par de ocasiones, verbigracia, leemos: "Y en poco mapa muchas esparcidas" (v. 139); "que nunca mucho a poco se reduce" (v. 370). Se trata de un claro recuerdo, especialmente en el primer caso, de algunas fórmulas gongorinas: "si mucho poco mapa les despliega" (Sol I, 194); "mucho océano y pocas aguas prenden" (Sol II, 75); "mucho

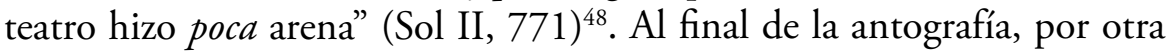
parte, encontramos estos versos:

Contar cuantas produce

flores y árboles fértiles la quinta

no da lugar a mi relación sucinta (vv. 367-369).

Como el lector atentó notará, estamos ante un nítido homenaje a uno de los fragmentos epitalámicos de la Fábula de Polifemo y Galatea:

Cuantas produce Pafo, engendra Gnido negras violas, blancos alhelíes,

48 Luis de Góngora, Soledades, ed. Robert Jammes, Madrid, Castalia, 2016, pp. 239, 431 y 539 . 
llueven sobre el que Amor quiere que sea tálamo de Acis ya y de Galatea (vv. 333-336) ${ }^{49}$.

Dejando a un lado las huellas gongorinas, un detalle del lenguaje que merece apuntarse es el particular uso del léxico. Tenemos, por un lado, una gran cantidad de expresiones vinculadas a 'lo raro y lo prodigioso': "biblioteca prodigiosa" (v. 5); "lo raro, lo exquisito del museo" (v. 8); "sus insignes maravillas" (v. 13); "curiosidades y primores" (v. 208); "rara compostura" (v. 263); "otros prodigios" (v. 268); "porque siempre lo raro / dio causas relevantes al reparo" (vv. 270-271); "lo admirable y lo raro" (v. 375); "no será prodigioso si no es claro" (v. 376). Del mismo modo, abundan las frases y construcciones ligadas a las ideas de admiración y sorpresa: "una torre eminente se descuella / en cuyo fin se admira / la estatua del galán de Deyanira" (vv. 19-21); "donde ha de ser todo suspensiones / la entrada ha de ofrecer admiraciones" (vv. 22-23); "a la curiosidad pasmos previene" (v. 25); "que admire todo por lo vario" (v. 165); "admirándose el Arte” (v. 186); "Aquí la vista admira dibujados / excelentes traslados" (vv. 198-199); "la vista admire artificiales" (v. 275); "y su variedad bella tanto admira" (v. 297); "en la que mira amenidad difusa, / y atónita, perpleja y admirada, / en suspensiones queda embelesada" (vv. 305-307); "demás que el fin de lo admirable y de lo raro" (v. 375). No son menos habituales las expresiones sobre el arte y el artificio del palacio: "Que dispuso la lima y sacó el arte" (v. 53); "los barros de Sagunto artificiosos" (v. 160); "Admirándose el Arte, dirá ahora / que ignora el modo, que el aliño ignora" (vv. 186-187); "muestran el artificio en lo luciente" (v. 208); "que aun en lo artificioso del aliño" (v. 233); "viéndose en ellos cuánto puede el arte" (v. 242); "Del resto que su casa adorna y pule, / el aliño es igual" (vv. 272-273); "la vista admire artificiales" (v. 275).

Con todo lo dicho sobre la elocutio, se puede concluir que no estamos ante un poema particularmente críptico desde la óptica del lenguaje. A pesar de ser un atento lector de Góngora, Uztarroz se decanta por una mayor sencillez expresiva en relación con su propósito de limitarse a 'trasladar aquella biblioteca prodigiosa'. Las escasas dificultades del texto pro-

49 Luis de Góngora, Fábula de Polifemo y Galatea, ed. Jesús Ponce Cárdenas, Madrid, Cátedra, 2019, p. 174. 
ceden únicamente de los referentes aludidos, pertenecientes al universo erudito del círculo lastanosiano.

\section{El CATÁlogo FlOral: VARIA FORTUNA EN LAS LETRAS barRocaS}

Desde las últimas décadas del siglo XVI, se va a popularizar en la poesía vernácula el recurso retórico de las congeries o 'enumeraciones' en diversas formas ${ }^{50}$. Para la literatura española, la crítica ha llamado la atención sobre el motivo de la abundancia natural o cornucopia, que a juicio de Woods consistiría en "the systematic listing in a more or less leisurely fashion of a multitude of different natural products and creatures, such as animals, flowers and fruits" ${ }^{51}$. Uno de los primeros en emplear esta técnica fue Luis Barahona de Soto en el canto III de Las Lágrimas de Angélica ${ }^{52}$. Ofrezco los primeros versos de la enumeración:
Ni la ciruela endrina o la melosa, que dicen que en color vence a la cera, ni la más tiesa, larga y generosa, que al sol enjuta largo tiempo espera,

50 Para una definición desde la retórica, véase Heinrich Lausberg, Manual de retórica literaria, trad. José Pérez Riesco, Madrid, Gredos, 1965, p. 134.

51 M. J. Woods, The Poet and the Natural World in the Age of Góngora, Oxford, Oxford University Press, 1978, p. 83. Véanse también Guillermo Díaz-Plaja, El espiritu del Barroco. Tres interpretaciones, Barcelona, Editorial Apolo, 1940; Emilio Orozco, "Sobre el concepto de bodegón en el barroco", en Temas del Barroco. De poesía y pintura, Granada, Universidad de Granada, 1947, pp. 17-22; José Fernández Montesinos, Estudios sobre Lope de Vega, Salamanca, Anaya, 1967; Rafael Osuna, "Una imitación de Lope de la 'Fábula de Polifemo' ovidiana”, Bulletin Hispanique, 70, 1-2 (1968), pp. 5-19; Rafael Osuna, "Bodegones literarios en el barroco español”, Thesaurus, XXIII, 2 (1968), pp. 206-217; Rafael Osuna, Polifemo y el tema de la abundancia de natural en Lope de Vega y su tiempo, Kassel, Reichenberger, 1996; Antonio Vilanova, Las fuentes $y$ los temas del Polifemo de Góngora, Barcelona, PPU, 1992, I, pp. 519-576; y Antonio Sánchez Jiménez, El pincel y el Fénix: Pintura y literatura en la obra de Lope de Vega Carpio, Madrid/Frankfurt, Iberoamericana/Vervuert, 2011, pp. 231-274.

52 Antes de la revolución italianista, como notó Osuna, op. cit., 1996, p. 23, contamos con uno de estos catálogos de productos naturales, a la zaga del modelo de los ofrecimientos de Polifemo a Galatea, en la Égloga VII de Juan del Encina. 
ni la castańa o nuez, ni la preciosa

guinda, y cereza, y la bellota, y pera,

pueden faltarte, ni la almendra y higo,

si con divino amor vives conmigo (III, 82) $)^{53}$.

Esta versión del motivo, que Lope cultivaría con ingenio a lo largo de toda su producción ${ }^{54}$, es una imitatio del pasaje ovidiano de las Metamorfosis en el que Polifemo ofrece sus riquezas a Galatea con el objeto de enamorarla (XIII, vv. 812-820):

sunt poma gravantia ramos,

sunt auro similes longis in vitibus uvae,

sunt et purpureae: tibi et has servamus et illas.

ipsa tuis manibus silvestri nata sub umbra

mollia fraga leges, ipsa autumnalia corna

prunaque non solum nigro liventia suco,

verum etiam generosa novasque imitantia ceras.

nec tibi castaneae me coniuge, nec tibi deerunt

arbutei fetus: omnis tibi serviet arbor ${ }^{55}$.

Tengo frutales que cargan sus ramas; tengo uvas semejantes al oro en extensas viñas, las tengo también color púrpura: para ti cuido éstas y también aquéllas. Tú misma con tus propias manos recogerás blandas fresas nacidas bajo la boscosa sombra, tú misma las silvestres cerezas del otoño y ciruelas, no sólo las que son moradas por su oscuro jugo, sino también las de buena raza y que imitan la cera nueva; y no te faltarán siendo mi esposa las castañas, ni te faltarán los frutos del madroño: todos los árboles estarán a tu servicio ${ }^{56}$.

53 Luis Barahona de Soto, Las lágrimas de Angélica, ed. José Lara Garrido, Madrid, Cátedra, 1981, pp. 204-205.

54 Se encuentra, por ejemplo, en las siguientes obras: Las burlas de Amor, Los amores de Albanio e Ismenia, la Pastoral de Jacinto, La Arcadia, El Isidro y Descripción de La Tapada.

55 Ovid, Metamorphoses. Vol. II (books 9-15), eds. Frank Justus Miller y G. P. Goold, Cambridge/London, Harvard University Press, 1984, pp. 284 y 286.

56 Ovidio, Metamorfosis, eds. Consuelo Álvarez y Rosa M. a Iglesias, Madrid, Cátedra, 2003, p. 698. 
Lo que aquí pretendemos explorar es un tipo de enumeración muy concreto algo menos atendido por la crítica: los catálogos de flores. Se trata de un motivo recurrente en las descripciones poéticas de jardines elaboradas por los ingenios italianos y espańoles del Seiscientos, aunque con algunos precedentes interesantes. Entre los primeros cultores del catálogo floral en las letras vernáculas modernas merecen recordarse, por su ligazón con los modelos clásicos, algunas octavas de las Stanze de Angelo Poliziano (I, 78-80):

Trema la mammoletta verginella con occhi bassi, onesta e vergognosa; ma vie più lieta, più ridente e bella, ardisce aprire il seno al sol la rosa: questa di verde gemma s'incappella, quella si mostra allo sportel vezosa, l'altra, che 'n dolce foco ardea pur ora, languida cade e 'l bel pratello infiora.

L'alba nutrica d'amoroso nembo gialle, sanguigne e candide viole; descritto ha 'I suo dolor Iacinto in grembo, Narcisso al rio si specchia come suole; in bianca vesta con purpureo lembo si gira Clizia palidetta al sole; Adon rinfresca a Venere il suo pianto, tre lingue mostra Croco, e ride Acanto.

Mai rivestì di tante gemme l'erba la novella stagion che ' 1 mondo aviva ${ }^{57}$.

57 'Tiembla la pequeña violeta virgen / con la mirada baja, honesta y vergonzosa; / mas, sonriente y bella, mucho más alegre / osa abrir el seno al sol la rosa: / esta se adorna con un verde botón, / aquella se muestra caprichosa, / la otra que, hasta hace nada, ardía en dulce fuego / lánguida cae y florece el bello prado. // Nutre el alba de amoroso rocío / amarillas, purpúreas, cándidas vïolas; / escrito tiene su dolor Jacinto en el regazo, / Narciso (como suele) en el arroyo se refleja; / en blanca veste con orla de púrpura / se gira hacia el sol la pálida Clicie; /Adonis renueva a Venus su llanto, / tres lenguas muestra Croco y ríe Acanto. // Nunca revistió de tantas gemas / la nueva estación que al mundo da vida' (Angelo Poliziano, Stanze/Orfeo/Rime, ed. Davide Puccini, Milano, Garzanti, 2020, pp. 66-68). 
Como evidencian los fragmentos citados, una de las claves de las que se sirve el poeta para pintar el idílico jardín de Venus es la presentación de toda una serie de flores (dos tipos de violas, la rosa, el jacinto, el narciso, el girasol, la anémona, el azafrán y el acanto). Las estrofas del erudito toscano ya ostentan los rasgos que dominarán los catálogos florales barrocos: la importancia de las notas cromáticas y la tendencia a personificar las flores, en gran medida a través de los relatos etiológicos descritos en las Metamorfosis ${ }^{58}$.

Con respecto a los posibles modelos clásicos, cabría comenzar apuntando que en las letras latinas la estética de catálogo se populariza después

58 Próxima al modelo de las Stanze de Poliziano, aunque dejando de lado los relatos etiológicos, puede recordarse la octava inserta por Fuscano en sus Stanze sovra la bellezza di Napoli: "Spiran poi tal'odor di loco in loco, / il bel narcisso col frondoso achanto, / il candido ligustro e 'l giallo croco / l'adorno giglio col vago amaranto, / le rose a guisa d'un vermiglio foco / et le vïole pallidette a canto, / ché l'alma intent'al riso et a l'odore / gode in se stessa et pende d'ogni fiore" (Cristiana Anna Addesso, Le Stanze del Fuscano sovra la bellezza di Napoli, Edizione critica, Nápoles, Università degli studi di Napoli Federico II, 2005, pp. 294-295). Asimismo, varios poemas neolatinos, a la hora de describir jardines, se van a servir de enumeraciones de plantas y flores semejantes. Baste traer a colación un par de ejemplos separados por unas cuantas décadas de distancia. En primer lugar, contamos con una sugerente epístola de setenta y ocho versos escrita por Alessandro Bracceso a Bernardo Bembo con el objeto de elogiar los jardines de Villa Careggi en tiempos de Lorenzo el Magnífico, donde se pondera cómo el hortus florentino supera a los vergeles clásicos y se enumeran árboles como el olivo, el mirto o la encina asociados a sus respectivas deidades (Hic olea est pallens Bellonae sacra Minervae, I et Veneri myrtus, aesculus atque (ovi). Véase Alexandri Braccii, Carmina, ed. Alexander Perosa, Firenze, Bibliopolis Libreria Editrice, 1943, pp. 75-77. Por otro lado, una poesia di villa neolatina de los últimos años del Quinientos había incluido un completo catálogo de flores y plantas, en gran medida inspirado por Columela. Nos referimos a la composición de Aurelio Orsi titulada Perettina, sive Syxti V Pont. Max. Horti Exquilini. Se trata de una obra encomiástica publicada por primera vez en 1588 y dedicada a la hoy fenecida Villa Perettina, perteneciente al papa Sisto V. Remitiéndose a la tradición de la nympha loci para celebrar el lugar, el poema incluye interesantes descripciones de las estancias y un catálogo en el que enumera varias flores y plantas valiéndose de una gran erudición clásica. Entre las varias especies vegetales recogidas, pueden recordarse las siguientes: viola, nardo, lila, cinamomo, acanto, perifollo, malva, adonis, jacinto, amaranto, azafrán, zarzaparrilla, rosa, mejorana, panaceas, parietarias, caléndulas, amapola, narciso, ligustro. Véase Aurelio Orsi, Perettina, sive Syxti $V$ Pont. Max. Horti Exquilini, Roma, apud Ioannem Martinellum, 1588, pp. 25-27. 
de la época augustea, sobre todo en la Antigüedad Tardía. Se pueden mencionar como ejemplos destacados previos a esta última etapa el citado bodegón de frutas que Polifemo ofrece a Galatea o, también en la epopeya metamórfica de Ovidio, el elenco de árboles presente en el relato de Orfeo (Libro X, 90-108). Más interesantes para nuestro propósito son dos catálogos florales, el del Culex o El Mosquito (poema perteneciente al llamado Apéndice Virgiliano) y el de Columela en su composición sobre los trabajos agrícolas. El primero se inserta en los versos finales de la obra cómica, cuando el pastor, tras despertarse del sueño en el que el espíritu del mosquito le atormenta por haber terminado con su vida, levanta un túmulo para el malogrado insecto sobre el que pretende depositar toda una cohorte de flores:

\section{hic et acanthus}

et rosa purpureum crescent pudibunda ruborem et violae omne genus; hic est et Spartica myrtus atque hyacinthus et hic Cilici crocus editus arvo, laurus item Phoebi decus ingens, hic rhododaphne liliaque et roris non avia cura marini herbaque turis opes priscis imitata Sabina chrysanthusque hederaeque nitor pallente corymbo et bocchus Libyae regis memor, hic amarantus bumastusque virens et semper florida tinus; non illinc narcissus abest, cui gloria formae igne Cupidineo proprios exarsit in artus; et, quoscumque novant vernantia tempora flores (vv. 398-410) ${ }^{59}$.

Aquí el acanto, la rosa casta de rubor de púrpura y violetas de todas clases crecerán. Aquí está también el mirto espartano y el jacinto, aquí el azafrán producido en los campos de Cilicia; también el laurel, gran gloria de Febo, aquí la adelfa y los lirios, el romero cultivado en regiones próximas, la hierba sabina que para los antiguos imitó al rico incienso, el crisantemo, la brillante yedra de pálido racimo, el boco acordándose del rey de

59 Virgil, Aeneid VII-XII/Appendix Vergiliana, translation by H. Rushton Fairclough, revised by G. P. Goold., Cambridge/London, Harvard University Press, 2000, p. 434. 
Libia; aquí el amaranto, el verde bumasto y el tino siempre en flor; no falta de allí el narciso, la vanidad ante su belleza con el fuego de cupido hizo arder sus propios miembros, y de todas cuantas flores renuevan las primaveras, el túmulo está sembrado por completo ${ }^{60}$.

El gaditano Columela, por su parte, incluiría otra enumeración de flores en el libro 10 de De re rustica (vv. 96-109), mencionando las violetas, el narciso, el lirio, el jacinto, la rosa o la adormidera, entre otras plantas. En lo que respecta a la variedad de elencos elaborados en la Antigüedad Tardía por ingenios como Ausonio, Claudiano o Sidonio Apolinar ${ }^{61}$, merece recordarse el pequeño catálogo floral diseñado por Claudiano en El rapto de Proserpina:

pratorum spoliatur honos: haec lilia fuscis intexit violis; hanc mollis amaracus ornat; haec graditur stellata rosis, haec alba ligustris. te quoque, flebilibus maerens Hyacinthe figuris, Narcissumque metunt, nunc inclita germina veris, praestantes olim pueros: tu natus Amyclis, bunc Helicon genuit; disci te perculit error, bunc fontis decepit amor; te fronte retusa Delius, hunc fracta Cephisus harundine luget ${ }^{62}$.

Las praderas son despojadas de su adorno; una mezcla los lirios con las sombrías violetas; a otra la adorna la flexible mejorana; avanza una florecida de rosas, blanca de alheñas otra. También te cortan a ti, Jacinto, que te afliges en tu lamentable figura, y a

60 Virgilio, Bucólicas/Geórgicas/Apéndice virgiliano, introducción general J. L. Vidal, traducciones, introducciones y notas por Tomás de la Ascensión Recio García y Arturo Soler Ruiz, Madrid, Gredos, 1990, pp. 460-461.

61 Véanse Curtius, op. cit., pp. 279-280; Michael Roberts, The Jewelled Style. Poetry and Poetics in Late Antiquity, Ithaca and London, Cornell University Press, 1989, pp. 59-62; y Jesús Hernández Lobato, "Introducción", en Sidonio Apolinar, Poemas, ed. y trad. Jesús Hernández Lobato, Madrid, Cátedra, 2015, pp. 56-61.

62 Claudian, On Stilicho's Consulship 2-3. Panegyric on the Sixth Consulship of Honorius. The Gothic War. Shorter Poems. Rape of Proserpina, translated by M. Platnauer, Cambridge/London, Harvard University Press, 1922, pp. 326-328. 
ti, Narciso, ambos ahora señeras flores de la primavera, en otro tiempo resplandecientes efebos; tú, Jacinto, naciste en Amidas, a éste lo engendró el Helicón; te mató a ti el viraje del disco, a éste lo engañó el amor de la fuente; te llora a ti el dios de Delos con su frente bajada, a éste Cefiso con sus cañas rotas ${ }^{63}$.

Se puede observar que el catálogo de Claudiano, poeta que influyó en Poliziano y que gozaría de gran popularidad en el Seiscientos, también presenta algunas de las flores ligadas a sus relatos etiológicos, alcanzando un grado de detalle mayor que los ejemplos anteriores. Entrando ya en la literatura barroca, merecen citarse un par de influyentes ejemplos italianos. En primer lugar, cabe recordar Lo Stato rustico, extensa composición didascálica de Giovan Vincenzo Imperiale, dividida en varios cantos, que conocería su primera edición en enero de 1607. En la sección consagrada a la descripción de la mansión genovesa que poseía el aristocrático autor, se incluye un amplio elenco de los vegetales que ornaban el jardín, con la presencia de numerosas flores. Se trata de un completo catálogo que se extiende a lo largo de más de cien versos (si dejamos de lado la sección centrada en las plantas aromáticas o la descripción del campo de amapolas), incluyendo flores como la rosa, el narciso, el ligustro, el lirio, el jazmín, el clavel, la violeta y el girasol.

Conservando los elementos citados (la importancia del cromatismo y los relatos etiológicos), el fragmento del vate genovés desarrolla otra idea popular en los catálogos florales del Seiscientos: el diálogo y competición entre las flores. Aparece, por ejemplo, el motivo de la rosa como la reina de las flores, que se dirige al sol como rey de los astros:
"Tu sorgi sol del cielo, io de la terra, tu nel ciel di zaffiro, io di smeraldo, tu di porpora tinto, io porporina, tu re degli astri et io de i fior reina” (X, vv. 974-977).

Varios versos después leemos que el clavel quiere proclamarse rey:

63 Claudiano, Poemas, vol. II, trad. Miguel Castillo Bejarano, Madrid, Gredos, 1993, pp. 217-218. Prescindiendo de los ricos matices cromáticos y de los relatos etiológicos, en un contexto narrativo similar de su Europa (vv. 63-71) había incluido Mosco un pequeño elenco de flores (narcisos, jacintos, violetas, serpol, azafrán y rosas). 
E mentre del rubin tutto gemmato

il suo vermiglio manto altier dispiega

l'infiammato Garofolo e gentile,

e da la plebe d'altri fior lontano

baldanzoso ne sorge il re de' fiori,

de la rosa reina emulo altero (X, vv. 1008-1013) ${ }^{64}$.

Dejando a un lado el interesantísimo modelo de Vincenzo Imperiale, no podemos olvidarnos de citar al principal poeta del barroco italiano, Giovan Battista Marino. Junto con los delicados tapices florales insertos en su obra maestra, el Adone, encontramos algunos catálogos en obras de una cronología más temprana. El idilio Europa, publicado por primera vez en 1607, incluye un bellísimo elenco de flores construido, entre otras fuentes, bajo el magisterio de la traducción quinientista del poema Europa de Mosco elaborada por Girolamo Muzio ${ }^{65}$, de las Stanze de Poliziano y del catálogo floral incluido en Lo Stato rustico. El sugestivo fragmento también pudo estar influido de manera genérica por El rapto de Proserpina de Claudiano, obra con la que ya estaba familiarizado el poeta partenopeo y de la que se sirve en algunos pasajes de su idilio. Cabe apuntar, asimismo, que en los idilios sobre Europa (de Mosco, de su traductor Muzio y de

64 'Tú surges del cielo, yo de la tierra; / tú en el cielo de zafir, yo de esmeralda, / tú teñido de púrpura, yo purpúrea, / tú rey de los astros y yo de las flores reina. // Y mientras del rubí todo enjoyado / su bermejo manto altivo despliega / el llameante y gentil clavel, / y, del vulgo de otras flores alejado, / surge atrevido el rey de las flores, I altivo émulo de la rosa reina' (Giovan Vincenzo Imperiale, Lo Stato Rustico, eds. Ottavio Besomi, Augusta Lopez-Bernasocchi y Giovanni Sopranzi, Roma, Biblioteca Italiana Testi e Studi, 2015, II, pp. 346-347).

65 "Qual segue i brevi, e candidi ligustri, / qual l'odorate e pallide viole; / colei ritengon le vivaci chiomi / del doglioso iacinto; e questa e quella / di purpureo color dipinge, e d'oro / il serpillo, et la persa; et là si vede / di vari fiori e d'amoroso mirto / tessere un molle cerchio al biondo crine. / Fra tutte l'altre la vezzosa Europa / l'aurate chiome e 'l delicato seno / di bianche rose ornata, et di vermiglie / tal si dimostra, qual purpurea rosa / tra fli altri fiori: o qual la bianca luna, / quando ella splende in su la mezzanotte / dal sommo ciel par de l'altre luci" (Girolamo Muzio, Rime diverse, Vinegia, Gabriel Iolito de Ferrari e fratelli, 1551, f. 146v. Las fuentes las anota Vania de Maldé en su edición de Giovan Battista Marino, La Sampogna, Parma, Fondazione Pietro Bembo/Ugo Guanda Editore, 1993, pp. 249-255). 
Marino) y en el de Proserpina la descripción se inserta en un contexto similar, la recogida de flores por parte de un personaje femenino. Citamos a continuación algunos fragmentos del pasaje mariniano, que en total enumera más de una decena de flores (amaranto, acanto, violeta, girasol, lirio, aciano, narciso, azafrán, ligustro, jacinto, amapola y rosa):

Sotto il bel piè ridea

tutto il popol de' fiori;

e, sí come a lor dea chini e devoti,

movendo tra se stessi

ambiziose gare,

quasi d'arabi incensi

le fean de' propri odor votive offerte.

[...]

La gentil mammoletta,

dal caro peso oppressa

di quelle vaghe piante,

d'amoroso pallor tinta la guancia,

tramortí di dolcezza in braccio a l'erba.

Clizia, d'Apollo amante,

per meglio vagheggiar de le due luci

il gemino levante,

levossi alta in sul gambo, e fu veduta

in un con le viole

a lei girarsi e ribellarsi al Sole.

[...]

Il candido ligustro,

che, qual minuta stella

imbiancando de l'orto il verde tetto

emulo del celeste,

segnava in esso un bel sentier di latte,

fatto stella cadente,

precipitò dal suo fiorito cielo,

e di candidi fiocchi

tempestò lievemente il prato erboso.

Il giacinto vezzoso,

libro de la Natura,

ne' fogli de le foglie

giá cancellata degli antichi lai 
la pietosa scrittura,

tutto per man d'amore

lineato a caratteri di sangue,

espresse queste note in un sorriso:

— Io cedo al tuo bel viso!-

$[\ldots]$

Alcun non fu di quella

adulatrice e lascivetta schiera,

che, per esser da lei mirato e còlto,

non le fêsse di sé cortese invito.

Ma la real fanciulla

sdegna i plausi vulgari

de la plebe odorata, e corre solo

dove festeggia e ride

folgorando tra l'erba

l'occhio di primavera,

la porpora de' prati,

la fenice de' fiori, ove la rosa,

bella figlia d'aprile,

sí come a lei sembiante

verginella e reina,

dentro la reggia de l'ombrosa siepe,

su lo spinoso trono

del verde cespo assisa,

de' fior lo scettro in maestá sostiene,

e, corteggiata intorno

da lasciva famiglia

di zefiri ministri,

porta d'or la corona e d'ostro il manto

(vv. 48-54; 64-74; 100-117; 127-149) ${ }^{66}$.

66 'Bajo el bello pie reía todo el pueblo de las flores. Y como si ella hubiese sido su diosa, inclinados y devotos, organizando entre ellos ambiciosas competiciones, le hacían ofertas votivas de sus propios olores, que eran casi como inciensos de Arabia [...]. La gentil violeta, cargada del peso de aquellas hermosas plantas, con las mejillas coloreadas de amorosa palidez, se desmayó de dulzura entre los brazos de la hierba. Clicie, enamorada de Apolo, para admirar mejor las dos luces del duplicado levante, se irguió sobre su tallo. Y fue vista entre las violas girarse hacia ella y rebelarse al Sol [...]. El blanco ligustro, que como una estrella menuda estaba emblanqueciendo el verde techo del huerto - -émulo del celeste-, trazaba un bello sendero de leche; 
Sumado a una caracterización particularmente rica de cada una de las flores bajo el signo del ingenio, en Marino encontramos altamente desarrollado el catálogo floral como una sociedad en miniatura ("popolo de" fiori”) consagrada a ponderar las bellezas de Europa y gobernada por la rosa-reina, a la cual se denomina 'ojo de la primavera', 'púrpura de los prados', 'Fénix de las flores' o 'bella hija de abril' ${ }^{\prime}$. El motivo de la rosa como reina de flores, muy extendido en la literatura barroca, presenta varios antecedentes de interés ${ }^{68}$. Por un lado, en la tradición provenzal, stilnovística y petrarquista se encuentra la siguiente analogía: 'del mismo modo que la rosa reina entre las flores, así mi dama reina entre las mujeres' ${ }^{69}$. Un ejemplo de esta imagen, que como vemos pervive en el idilio de Marino, la tenemos en el soneto CCXLIX del Canzoniere: "I' la riveggio starsi hu-

convertido en una estrella cadente, se precipitó desde su florido cielo y de blancos copos tempestó levemente sobre el prado herboso. El encantador Jacinto, libro de la Naturaleza, ya ha tachado en las hojas de sus hojas la piadosa escritura de los antiguos lamentos; dibujado por mano del Amor con caracteres de sangre, expresa estas notas en una sonrisa: Yo me someto a tu bello rostro. (...) No hubo entre aquella lasciva y lisonjera tropa ninguna que, para ser contemplada y recogida por ella, no le hiciese una cortés invitación. Pero la regia joven desdeña los aplausos vulgares de la olorosa plebe, y corre solo donde ríe y celebra, fulgurando entre la hierba, el ojo de la Primavera, la púrpura de los prados, la fénix de las flores; donde la rosa, bella hija de abril -semejante a ella como virgen y reina-, dentro de la umbrosa corte de los setos, asida de la verde mata sobre el espinoso trono, sostiene con majestad el cetro de las flores. Y cortejada a su alrededor por la lasciva familia de los Céfiros ministros, porta la corona de oro y el manto de púrpura' (Ibidem, pp. 249-255).

67 Varias de las notas sobre la flor reina se repiten en el elogio de la rosa incluido en el tercer canto del Adone: "E tu fastosa del tuo regio vanto / porti d'or la corona e d'ostro il manto. // Porpora de' giardin, / pompa de prati, / gemma di primavera, occhio d'aprile" (octavas 157 y 158; Marino, L’Adone, ed. Giovanni Pozzi, Milano, Adelphi, 1988, p. 182).

68 Una prueba de su popularidad en Italia nos la ofrece el catálogo de epítetos que emplearon algunos poetas para describir su majestad compilados por Giovan Battista Spada (donna de' fiori, fenice de' fiori, fiore de' fiori, idolo de' fiori, imperatrice de' fiori, monarchessa, de' fiori, regina de' fioriti odori, reina del popolo Fiorito, sole deffiori) en Giardino de gli epititi, traslati et aggiunti poetici italiani, Bologna, per l'herede di Vittorio Benacci, 1648, pp. 654-655.

69 Véase Giulia Ravera, Topoi trobadorici nei Rerum vulgarium fragmenta, Milán, Università degli Studi di Milano, 2014, pp. 314-317. 
milmente / tra belle donne, a guisa d'una rosa / tra minor' fior"'70.

Por otro lado, desligada de este tipo de poesía amatoria, la imagen parece remontarse a algunos textos de la literatura antigua. Como notaba el carmelita Jerónimo Gracián a finales del siglo XVI,

es la rosa según decía Safo, poetisa griega, inventora de los versos sáficos, y Anacreonte, también griego y antiquísimo poeta, a los cuales cita Achiles Tacio y Clemente Alexandrino, reina de las flores, atavío de la tierra, hermosura de las plantas, ojo de las verduras, color que hermosea las mejillas del prado, risa del mundo, corona de las musas y es consagrada a las gracias $^{71}$.

El religioso se refiere, aparte de al corpus anacreóntico y a sus varios versos consagrados a la rosa, a un fragmento de la novela de Aquiles Tacio Leucipa y Clitofonte en el que se elogia la flor:

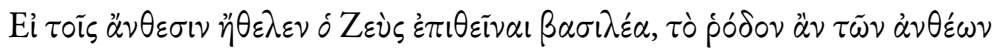

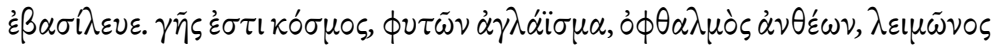

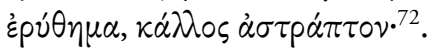

Si Zeus hubiese querido dar a las flores una reina, la rosa hubiera sido reina de las flores: es ornato de la tierra, gala de las plantas, ojo de las flores, rubor de la pradera, hermosura destellante ${ }^{73}$.

70 'Yo la contemplo cuando se muestra humildemente, entre mujeres hermosas, del mismo modo que una rosa entre flores menores' (Francesco Petrarca, Canzoniere, ed. Marco Santagata, Milano, Mondadori, 2019, p. 1016).

71 Jerónimo Gracián, Obras del maestro Gerónimo Gracián, Madrid, Viuda de Alonso Martín, 1616, p. 309. Antes de esta edición póstuma de la producción del religioso, el texto se podía leer en una traducción italiana: Tratatto del giubileo dell'anno santo del P. M Girolamno Gratiano, Roma, Apresso Luigi Zanetti, 1599, p. 315.

72 Achilles Tatius, Leucippe and Clitophon, ed. Stephen Gaselee, Cambridge/London, Harvard University Press, 1984, p. 56.

73 Longo - Dafnis y CloelAquiles Tacio - Leucipa y ClitofontelJámblico - Babilónicas (resumen de Focio y Fragmentos), eds. Máximo Brioso Sánchez y Emilio Crespo Güemes, Madrid, Gredos, 1982, p. 197. Dentro de la rica tradición poética de la Antigüedad Tardía, merece recordarse la imagen de la rosa como 'reina de olores' inserta en un breve poema de Tiberiano: "inter ista dona veris gemmeasque gratias / omnium regina odorum vel colorum Lucifer / auriflora praeminebat, flamma Diones, rosa" ("Entre estos 
Sin duda, el escritor alejandrino, con una serie de imágenes que recuerdan a los versos de Marino, ofrece uno de los más sugestivos testimonios de la metáfora en la Antigüedad.

Orillando este excurso sobre la rosa, se hace necesario decir un par de palabras sobre los catálogos florales confeccionados por los poetas españoles previos a Uztarroz. Sin pretender realizar una historia exhaustiva del motivo en las letras españolas, cabe apuntar que las muestras más interesantes y desarrolladas se encuentran en textos posteriores a 1610, en muchas casos en poemas descriptivos de palacios y jardines: la Descripción de Buenavista de Baltasar Elisio de Medinilla (hacia 1614), la Descripción de La Tapada de Lope de Vega (1614-1621), Describe una recreación y casa de campo de un valido de los señores Reyes Católicos don Fernando y doña Isabel de Quevedo (1617-1620), Aula Dei de Miguel Dicastillo (1635-1636), el Paraíso cerrado de Soto de Rojas (1640-1651), etc. Varios de estos catálogos evidencian las huellas de la revolución gongorina y, por ello, merece la pena recordar uno de los modelos hispanos que tuvo más influjo, el romance del racionero cordobés Esperando está la rosa ${ }^{74}$, escrito en torno a 1609. La composición, en la línea de la de Marino, no solo incide en las notas cromáticas y en los relatos etiológicos, sino que se sirve de las flores como metáfora de un reino encabezado por la rosa y con el resto de flores como cortesanas:

\author{
Esperando están la Rosa \\ cuantas contiene un vergel
}

dones primaverales y gratas perlas, reina de todos los aromas o lucero de los colores, descuella la flor dorada de la rosa, llama de Dione'). Doy la traducción de Serrano Cueto en "Vere novo florebat humvs. La primavera nupcial en la tradición del epitalamio latino”, en Calamus renascens. Revista de humanismo y tradición clásica, 16 (2015), pp. 267-288 (p. 273). El texto puede leerse en Minor latin poets, II, eds. y trads. J. Wight Duff and Arnold M. Duff, Cambridge/London, Harvard University Press, p. 558.

74 "Hasta cuarenta y tantos testimonios antiguos han transmitido este romance, que sirvió de modelo a docenas de poetas españoles y portugueses, como el P. Valentín de Céspedes, Juan de Ovando y Santarén o André Nunes de Sylva. La razón es clara: se trata de una pequeńa obra maestra en que el autor, en plena madurez, describe un jardín en primavera con términos cortesanos" (Antonio Carreira, Flores y jardines en la poesía del Siglo de Oro, Santa María de Cayón, Ayuntamiento de Santa María de Cayón, 2013, p. 22). Sin duda, una de las imitaciones más interesantes del modelo gongorino la encontramos en el complejo catálogo floral con el que Pedro Soto de Rojas concluye su Paraíso cerrado (vv. 945-1079). 
flores, hijas de la aurora,

bellas cuanto pueden ser.

Ella, aunque con majestad,

no debajo de dosel

sino sobre alfombras verdes,

purpúrea se dejó ver;

como a reina de las flores,

guarda la ciñe fiel,

si son archas las espinas

que en torno de ella se ven (vv. 1-12).

El poema de Góngora utiliza también la metáfora del 'pueblo' para referirse a otras plantas ("vulgo de esotras hierbas", v. 21) y las metamorfosis características de las flores envolviéndolas en la trama cortesana:

Las colores de la reina

vistió galán el Clavel,

príncipe que es, de la sangre,

y aun aspirante a ser rey.

En viéndola, dijo: “زay!”,

el Jacinto, y al papel

lo encomendó, de sus hojas,

por que se pueda leer.

Ámbar espira el vestido

del blanco jazmín, de aquel

cuya castidad lasciva

Venus hipócrita es.

La fuente deja, el Narciso,

que no es poco para él,

y ya no se mira a sí,

admirando lo que ve.

Oh, qué celoso está el Lilio,

un mal cortesano que

calza siempre borceguí:

debe de ser portugués (vv. 37-56) ${ }^{75}$.

75 Luis de Góngora, Romances, ed. Antonio Carreira, Barcelona, Quaderns Crema, 1998, II, pp. 187-193. 
En el romance de Góngora, los relatos etiológicos de algunas flores (como el del jacinto y el del narciso) pasan a ser leídos a la luz de la alegoría en la que se insertan y, a un mismo tiempo, aparecen nuevos conceptos ingeniosos. El lirio, por ejemplo, parece celoso por su color azul y por su tallo da la impresión de que lleva calzado de borceguí, popular entre los portugueses. Asimismo, Góngora retoma el motivo del clavel como émulo de la rosa o aspirante a rey, que ya habíamos visto en los versos de Vincenzo Imperiale. El clavel como par masculino de la rosa, según ha estudiado Álvaro Alonso, aparece por primera esbozado en textos escritos entre las décadas de 1560 y 1590 por autores como Luis de Milán, Juan de Timoneda o Francisco de Aldana, aunque conocerá su pleno desarrollo en la poesía barroca ${ }^{76}$.

Antes de entrar en el examen del catálogo elaborado en la Descripción de las antigüedades y jardines de D. Vincencio Juan de Lastanosa, nos gustaría apuntar una última idea. En el examen de los bodegones frutales o cortejos rústicos, algunos estudiosos han sugerido el paralelismo que podría establecerse entre el motivo poético y el florecimiento de las naturalezas muertas en las últimas décadas de siglo XVI en Espańa, Flandes e Italia ${ }^{77}$. Del mismo modo, cabría postular la correspondencia entre las representaciones florales en las arti sorelle a través del subgénero conocido como florero, de gran popularidad en la España de los Austrias menores. De hecho, se trata de una idea bosquejada por Emilio Orozco, quien además ya había vinculado el interés descriptivo en la poesía barroca con el gusto por la poesía latina de la decadencia. Me permito insertar su elocuente observación:

El barroquismo se ha impuesto en lo literario cuando el clasicismo perdura aún en la plástica. Así, el recreo ante la belleza de la flor, el florero y hasta el bodegón, se da antes en la poesía. El tema de las flores

76 Álvaro Alonso, "El clavel como motivo poético", en I canzoneri di Lucrezia: atti del convegno internazionale sulle raccolte poetiche iberiche dei secoli XV-XVII, eds. Andrea Baldissera y Giuseppe Mazzocchi, Ferrara, Unipress, 2005, pp. 193-205 (p. 197). Un ejemplo ilustrativo de la pervivencia de este motivo a lo largo de los siglos lo encontramos en la canción española ¿Será una rosa?, compuesta por Francisco de Val e interpretada con gran éxito por Gracia Montes en la década de los 50: “¿Será una rosa, será un clavel? / El mes de mayo te lo diré. / ¿Será una rosa, será un clavel? / Las golondrinas vendrán con él. // Torero como su pare / será si fuera un clavel; / si es una rosa qué guapa, / qué guapa tiene que ser".

77 Orozco, op. cit.; Sánchez Jiménez, op cit., pp. 233-263. 
era ya viejo en las letras, aunque precisamente era debido, en aparte, a la persistencia de temas de una época barroca: de la poesía latina de la decadencia. En Garcilaso son aún simples anotaciones, pero ya con perfiles precisos y color. Una cierta morosidad descriptiva se acentúa en Espinosa; pero los nuevos temas triunfan con Rioja, López de Zarate, Góngora, Quevedo, Lope y Soto, entre otros. En ellos encontramos no sólo el florero y el bodegón, sino también la visión decorativa equivalente a la guirnalda de flores y frutos del ornato barroco ${ }^{78}$.

A los lúcidos apuntes del maestro granadino cabría añadir un par de notas. En primer lugar, se trata en ambos casos de representaciones altamente artificiosas, que no pretenden mostrar ninguna realidad tal como era. Por otro lado, en la popularidad de ambos tratamientos debió jugar un papel importante el desarrollo de la jardinería en sus diversas formas que conoció el siglo XVI, con la publicación de numerosos tratados especializados. A modo de botón de muestra, baste recordar un lienzo de uno de los pioneros y maestros del género, el espańol de origen flamenco van der Hamen, buen amigo de Lope de Vega:

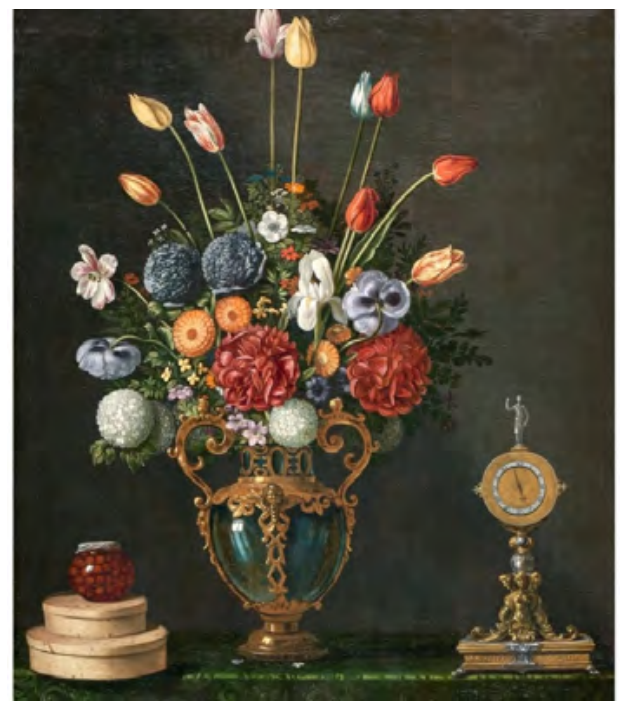

Fig. 6, Juan van der Hammen y León, Bodegón con florero y perro (fragmento), 1625, óleo sobre lienzo, 228,5 x 100,5 cm, Madrid, Museo del Prado

78 Orozco, op. cit., pp. 20-21. 
Se trata de una obra pintada en torno a 1625 que hace pareja con otra muy similar, presente también en el Museo del Prado. El lujoso jarrón de bronce y cristal recoge toda una serie de flores dispuestas con gran simetría y sentido compositivo, sin pretender resultar naturalista. Entre las flores representadas encontramos peonías rojas, lirios, gladiolos, geldres y tulipanes. Esta última flor, de gran popularidad en el Seiscientos, la recogerá Uztarroz en su catálogo.

Entrando ya en la cornucopia de la descripción que nos ocupa, su estructura es la siguiente:

Catálogo floral (308-371)

3.3.1. Comparación de las flores con estrellas (vv. 308-312)

3.3.2. Alhelíes (vv. 313-314)

3.3.3. Narciso (vv. 315-320)

3.3.4. Tulipanes de Francia (vv. 321-328)

3.3.5. Rosa (vv. 329-340)

3.3.6. Clavel (vv. 341-346)

3.3.7. Azucena (vv. 347-350)

3.3.8. Lirio (vv. 351-360)

3.3.9. Jazmín (vv. 361-366)

3.3.10. Recusatio para poner fin a la relación (vv. 367-369)

Como puede observarse, el texto se abre con una popular analogía en las letras barrocas, la comparación de las flores con las estrellas:

Siguen de Flora las hermosas huellas las flores, que pudieran ser estrellas errantes, por lo vario y por lo hermoso, aunque en la duración no lo parecen, porque más que otras plantas permanecen (vv. 308-312).

Aunque no es el objeto de estudio ahondar en la génesis y naturaleza de esta imagen $^{79}$, cabe apuntar que también fue empleada por otros ingenios espa-

79 Para una primera aproximación, véanse Eugenio Asensio y M. J Woods, "Formas y contenidos: la silva y la poesía descriptiva", en Historia de la literatura española, dir. Francisco Rico, Barcelona, Crítica, 1983, III, pp. 676-685; y José Fernández Dougnac, Estudio y edición del poema Granada de Agustín Collado del Hierro (tesis 
ñoles a la hora de celebrar suntuosos jardines. Baste recordar los ejemplos de Francisco de Quevedo en Describe una recreación y casa de campo de un valido de los señores Reyes Católicos y el Paraíso cerrado de Pedro Soto de Rojas ${ }^{80}$ :

Parte del cielo que cayó en la tierra

adonde, con viviente astrología, los ojos de la noche pinta el día, en quien las flores y las rosas bellas

dan retrato y envidia a las estrellas (vv. 6-10) ${ }^{81}$.

De los Céfiros blancos sacudida, perfumes llueve y ámbares respira, cuando, encendido en hermosura, el suelo, gozando tanto cielo, si por términos breve, en los jardines, de mosquetas los nieva y de jazmines, mientras las flores bellas retrato dan con alma a las estrellas (VII, vv. 945-952) ${ }^{82}$.

A continuación, Uztarroz consagra unos versos primero a los alhelíes y posteriormente al narciso, aludiendo a un par de notas cromáticas en el primer caso y a la repetida imagen de la metamorfosis en el segundo, acentuando su carácter de exemplum moral:

el narciso que el blanco de sus hojas

corona el rubio rey de los metales, y en él también acuerda las congojas que un tiempo le causaron los cristales, será ejemplo fatal de la agonía que ocasiona la ciega filaucía (vv. 315-320).

doctoral), Málaga, Universidad de Málaga, 2015, pp. 400-401.

80 La cercanía entre los pasajes de ambos poetas ha sido apuntada por Eugenio Asensio, "Un Quevedo incógnito: las silvas", Edad de Oro, II (1983), pp. 13-48 (p. 43).

81 Francisco de Quevedo, Obra poética, ed. José Manuel Blecua, Barcelona, Planeta, 1981, pp. 233-234.

82 Pedro Soto de Rojas, Paraíso cerrado para muchos, jardines abiertos para pocos/Los fragmentos de Adonis, ed. Aurora Egido, Madrid, Cátedra, 1981, p. 133. 
Lo más interesante de la tópica imagen es, sin duda, el uso del vocablo filaucía, poco común en las letras españolas de la época. Mucho más sugerente, en cambio, resulta la siguiente flor evocada, el tulipán ${ }^{83}$ :

\section{La copiosa abundancia}

que tiene más beldad que no fragancia,

los tulipanes que la Francia cría

y tu curiosidad pródiga envía,

desarrollan aquí vistosamente,

tanto esplendor luciente

y tanta variedad, que no hay colores

que puedan dibujar sus resplandores (vv. 321-328).

Se trata de la única nota realista en un catálogo edificado sobre convenciones literarias y que ilustra de manera inequívoca los intereses florales en el círculo lastanosiano. Según relata Uztarroz y leemos también en otros testimonios como la Narración de 1662, la afición de Lastanosa por la botánica le llevaba a encargar flores exóticas a sus amistades extranjeras como Juan Bautista Dru en Lyon, La Faía en Burdeos, Pierre Morin en París Vincenzo Mariscotti en Bolonia o el propio Filhol en Toulouse. En el caso del erudito tolosano, sabemos que poseía "la abundancia de Amaltea, en la diversidad de semillas, raíces, flores, simples, drogas, sales, gomas, quintas esencias" ${ }^{84}$. La anécdota del envío de semillas de tulipanes debió de interesar especialmente al poeta aragonés, ya que también daba cuenta de ella en un soneto recogido por Ricardo del Arco y Garay:

83 Cabe recordar, como ya notaba Ponce Cárdenas, op. cit., 2018, p. 264, que los tulipanes no se encuentran entre las flores más comunes mencionadas en estos catálogos barrocos, exceptuando casos como el de El jardin florido del conde de Monterrey de Juan Silvestre Gómez (v. 321) o el Paraíso cerrado de Pedro Soto de Rojas (v. 1069). Entre las poesie di villa italianas, puede recordarse su mención en el tardío poema sobre Versalles compuesto por Lodovico Adimari: "Mirasi allor l'Anemonetto altero / far dolce oltraggio a la Viola umile, / Il Narciso e il Giacinto aver l'intero / vanto fu'l Croco, e Tulipan gentile" (Poesie di Lodovico Adimari, patrizio fiorentino e gentiluomo della camera del Serenissimo di Mantova, alla maestà del gloriosissimo e cristianissimo rè Lodovico XIV il Grande, s. 1., s. i., 1691, f. 39r).

84 Uztarroz, op. cit., 1644, p. 17. 
Esas flores que ilustran los jardines, Gelio, de nuestro amigo Lastanosa, a la industria se deben oficiosa de quien Tolosa aplaude en sus confines.

Filhol, digo, que excede a los jazmines en candor y en fragancia virtuosa: este, pues, de su quinta artificiosa traslada a Huesca flores Paladines.

Varia y florida es ya la primavera, pues de los tulipanes los colores la matizan y la hacen lisonjera.

Admiras, ¡oh Gelio!, sus primores, pero si tu atención lo considera, verá que Francia es flor, y así dél flores ${ }^{85}$.

A continuación el poema ofrece las descripciones de la rosa y el clavel, en una línea semejante a la ensayada por Góngora en su romance:

Aquí vive la rosa tan ufana aumentando carmín a la mañana, a quien el aire bebe el aljófar que en ella el alba llueve, y coronada de oro su majestad aumenta y su decoro; pero, jay, dolor!, que el bello imperio dura la edad de un sol, que siempre la hermosura suele vivir instantes; así pues de la rosa las flamantes hojas se desvanecen y con las negras sombras se obscurecen. Preso el clavel se mira porque contra la rosa se conspira, y aunque las cańas son leves prisiones, las tienen merecidas las traiciones,

85 Arco y Garay, op. cit., 1934, pp. 83-84. 
que no hay flor tan altiva y ambiciosa

que el cetro niegue a la purpúrea rosa (vv. 329-346).

Por un lado, a la imagen de la rosa como reina de las flores le siguen una serie de notas tópicas sobre su color (el "carmín” que da a la mañana, el oro de su corona), su naturaleza regia y sobre la fugacidad de su belleza. Por otro, el clavel se compara con un altivo "prisionero" que ha querido quitarle la corona a la rosa. Si bien es probable la inspiración gongorina de la imagen (y quizá del pasaje en general), la tópica también puede provenir de algunos fragmentos de Aula Dei, poema cuyo conocimiento por parte de Uztarroz hemos probado con anterioridad. En la silva religiosa Miguel Dicastillo incluía los siguientes versos:

La rosa, que preciada de escarlata con tantos resplandores

el imperio se usurpa de las flores, y como reina del jardín se trata: en su misma beldad desvanecida frágil retrata nuestra humana vida [...]

En el clavel hermoso, príncipe de las flores orgulloso, regia púrpura admiro ${ }^{86}$.

Si bien la caracterización que Dicastillo realiza del clavel es algo más sencilla, no se debe descartar que Uztarroz lo tuviese en mente a la hora de pintar su pequeño popolo dé fiori. Finalmente, el catálogo se cierra con la evocación de otras tres flores: la azucena, el lirio y el jazmín. Mientras que este último solo se presenta como adorno del jardín, las otras dos plantas aparecen en cierta medida personificadas:

El azucena en tantas candideces

dice que en su pureza no hay dobleces,

que no es poca ventura

hallarse sin engaño la blancura;

y el lirio, contemplándose en su plata,

86 Egido, op. cit., p. 52. 
de sus hojas lo cárdeno desata

$y$ en letras de oro su fineza escribe;

pero el casto retiro no percibe

las líneas de su amor ni sus antojos, antes bien el silencio en sus enojos publica cuerdamente y a sus quejas tuerce el rostro y les niega las orejas; que si escuchara el ruego, presto Cupido introdujera el fuego (vv. 347-360).

Por un lado, la candidez de la azucena la convierte en un símbolo de la pureza y, en lo que respecta al lirio, cabe la posibilidad de que, por la alusión a su reflejo en el agua ('su plata'), no se esté refiriendo al iris germanica o lirio cárdeno, sino a la eichhornia crassipe, conocida en espańol como jacinto de agua o lirio acuático, planta oriunda de América e igualmente de color violáceo con toques dorados, tal como señalan los versos del poeta. De ser así, se explicarían las "letras de oro" y la publicación de sus "quejas" como una suerte de alusión al relato etiológico del jacinto, con la historia del efebo que Apolo asesinó accidentalmente mientras participaban en una competición de lanzamiento de disco. Según Ovidio, tras la trágica muerte del joven y su transformación en flor, Apolo habría escrito sus dolientes gemidos en la hojas a través de los caracteres "AI AI" (Met, XIII, vv. 394-398).

\section{Conclusiones}

La poesía descriptiva de palacios, villas y jardines elaborada en España desde finales del siglo XVI supone un precioso entrecruzamiento entre la historia, el arte y la literatura convertido en muchos casos en la única memoria superviviente de toda una serie de realidades culturales, artísticas y arquitectónicas fenecidas. Concretamente, en la Descripción de las antigüedades y jardines de D. Vincencio Juan de Lastanosa, Uztarroz nos ofrece, gracias a su privilegiada óptica de historiador y poeta, una detallada y sugestiva visión del coleccionismo aristocrático en el Seiscientos español. El estudio ha tratado de poner de manifiesto cuáles son algunas de las claves que articulan la representación poética del palacio de Lastanosa. Entre 
ellas, cabe recordar la importancia que el ingenio aragonés concede a ciertos detalles como la llamativa estatua de Alcides, las varias colecciones de medallas o al recuerdo de la malograda mujer de Lastanosa.

Por otra parte, el análisis del motivo poético del catálogo floral y su encarnación en los versos de Uztarroz ha evidenciado la necesidad del comparatismo como herramienta para lograr un entendimiento cabal de la literatura áurea. Gracias al examen de algunos textos clásicos y contemporáneos, se ha pretendido mostrar la relevancia de un detalle al que tradicionalmente no se le había prestado demasiada atención y que resulta fundamental para entender hasta qué punto eran realistas las descripciones de villas y jardines que compusieron varios poetas auriseculares. $\mathrm{Si}$ bien hemos querido aquí bosquejar varias líneas generales sobre el tema, sería recomendable que en un futuro se profundizase en él, tratando de acotar su cronología y estableciendo con la mayor precisión posible su relación con los modelos clásicos e italianos. 